\title{
Application of Comprehensive Geophysical Prospecting Method in the Exploration of Coal Mined-Out Areas
}

\author{
Xiao Luo, ${ }^{1,2,3}$ Shuang Gong $\mathbb{B D}^{4,5,6}$ Zhonggang Huo, ${ }^{1,2}$ Hongyan Li, ${ }^{1,2}$ and Xinpin Ding ${ }^{1,2}$ \\ ${ }^{1}$ Mine Safety Technology Branch of China Coal Research Institute, Beijing 100013, China \\ ${ }^{2}$ State Key Laboratory of Coal Mining and Clean Utilization (China Coal Research Institute), Beijing 100013, China \\ ${ }^{3}$ School of Mining, Liaoning Technical University, Fuxin 123000, China \\ ${ }^{4}$ School of Energy Science and Engineering, Henan Polytechnic University, Jiaozuo 454000, China \\ ${ }^{5}$ Henan Key Laboratory for Green and Efficient Mining \& Comprehensive Utilization of Mineral Resources, \\ Jiaozuo 454000, China \\ ${ }^{6}$ Collaborative Innovation Center of Coal Work Safety, Jiaozuo 454000, Henan Province, China
}

Correspondence should be addressed to Shuang Gong; gongcumtb@126.com

Received 4 April 2019; Revised 26 June 2019; Accepted 15 July 2019; Published 8 August 2019

Academic Editor: Hossein Moayedi

Copyright (C) 2019 Xiao Luo et al. This is an open access article distributed under the Creative Commons Attribution License, which permits unrestricted use, distribution, and reproduction in any medium, provided the original work is properly cited.

Due to the influence of mining technology, some coal mines will leave mined-out areas (or goafs) in the rock mass after mining. If the distribution law and influence scope of mined-out areas cannot be accurately explored and controlled, it will bring great potential safety hazards to subsequent coal mining and cause serious harm to adjacent houses, roads, bridges, railways, and so on. The unmanned aerial vehicle (UAV) aerial survey is used to accurately acquire the three-dimensional model of the slope in the key area of Yuanbaoshan open-pit coal mine, which provides basic information for the real-time visualization of the open-pit mine and the establishment of the engineering geological research profile. And the distribution of mined-out areas and water accumulation in the coal mine are investigated in detail by using the comprehensive geophysical prospecting method of the transient electromagnetic method (TEM) and controlled source audio-frequency magnetotellurics (CSAMT). Then, the borehole detection method is used to verify the goaf range obtained from comprehensive geophysical prospecting, and the results show good consistency. In addition, based on the results of borehole exploration and the comprehensive analysis of the borehole image, the instantaneous water level elevation in goaf and the development height of the water-conducting fracture zone and caving zone are concluded. Finally, the distribution of coal mined-out areas in the exploration area is obtained, and the results show that through the use of the transient electromagnetic method and controlled source audio-frequency magnetotellurics method, combined with drilling detection methods, the purpose of accurate exploration of mined-out areas in coal mines can be achieved.

\section{Introduction}

In recent years, the large-scale exploitation and utilization of coal resources in China has brought huge economic and social benefits. At the same time, the overexploitation of coal has formed a large number of mined-out areas (or goafs) underground. The coal mined-out area has led to large-scale surface subsidence. Ground buildings, transportation facilities, and living infrastructure and land have been seriously damaged [1-5]. It has brought great threat to people's lives and production in the mining area and has caused serious impact and harm to China's economic construction and social stability. Therefore, finding out the specific situation of the mined-out area and avoiding the occurrence of disastrous geological phenomena such as collapse, water inrush, and roof caving have become urgent problems to be solved. Furthermore, the open-pit mining method in coal mining, with its advantages of full utilization of resources, high production efficiency, low cost, and good working conditions, is taking up an increasing proportion in China's coal mining $[6,7]$. However, for a long time, many small coal mines in China have adopted room-and-pillar mining methods, leaving many goafs when they are closed. The size, location, and depth of these holes are uncertain, and with the 
progress of open-pit mining above the concealed goaf and the passage of time, the holes gradually collapse. It is difficult to grasp the actual void stratum. Because the roof collapse of underground goaf is concealed, there is almost no warning in advance. Once the collapse occurs, it may cause serious safety accidents. The operation of super-large equipment in the open-pit mine has great potential safety hazards in the upper part of goaf. Once the equipment falls into the goaf, it may cause casualties and equipment damage.

Quantitative evaluation of goaf stability requires accurate geological data, and determining the exact location of goaf is the primary task of engineering geological investigation. The conventional survey method is to detect the core by arranging more boreholes $[8,9]$. This method is essential to determine the location of the goaf. However, the implementation of drilling often costs a lot of time and money, especially for some projects under construction. Even if there is a guarantee of drilling funds, but the exploration time is limited, it may not be allowed to implement more boreholes or the exploration site also has limitations on drilling, which requires the study of rapid and accurate exploration technology of goafs or minedout areas. Compared with the borehole detection method, the geophysical method is widely used in detection because of its high efficiency and nondestructive characteristics [10-14]. At present, there are many geophysical techniques. Each detection method has certain effect but also has limitations. For example, ground penetrating radar has strong resolution but limited depth [15, 16]. Seismic and Rayleigh wave-layering ability is strong, but the response to water filling is not obvious [17]. The direct current method is greatly affected by grounding conditions and topographic fluctuations $[18,19]$. The transient electromagnetic method is less affected by topography and has better detection effect on water accumulation in goaf of the coal mine, but it has no obvious response to highresistance anomaly [20-23]. It can be seen that the previous comprehensive geophysical methods are mostly applied to hydrogeological conditions, landslides, and groundwater exploration. However, there are few studies on the exploration of goaf and water-bearing areas in coal mines. And the feasibility and validity of the comprehensive geological exploration method applied to the underground goaf are rarely reported. According to the physical characteristics of different mined-out areas, the main technical way to solve these problems is to adopt the comprehensive geophysical prospecting method with necessary drilling verification. However, its actual exploration effect needs further research and verification.

In the present study, the unmanned aerial vehicle (UAV) aerial survey is used to accurately acquire the three-dimensional model of the slope in the key area of Yuanbaoshan open-pit coal mine, which provides basic information for the real-time visualization of the open-pit mine and the establishment of the engineering geological research profile. And the distribution of mined-out areas and water accumulation in the coal mine are investigated in detail by using the comprehensive geophysical prospecting method of transient electromagnetic method
(TEM) and controlled source audio-frequency magnetotellurics (CSAMT). Then, the borehole detection method is used to verify the goaf range obtained from comprehensive geophysical prospecting. In addition, based on the results of borehole exploration and the comprehensive analysis of the borehole image, the instantaneous water level elevation in goaf and the development height of water-conducting fracture zone and caving zone are concluded. Finally, the comprehensive results and the predicted goaf range are analyzed and discussed.

\section{General Situation of Exploration Area}

2.1. General Geological Situation. Yuanbaoshan open-pit coal mine is located $35 \mathrm{~km}$ northeast of Chifeng City, Inner Mongolia Autonomous Region, China, as shown in Figure 1. The main coal seams in the mine are large in thickness, shallowly buried, and there are many production mines and small coal pits nearby. There are five closed small coal mines in the first mining area. Because all these small coal mines are roof-and-pillar mining, a large number of underground void areas or mined-out areas are left behind, which poses a serious threat to the safety of production on the spot. In recent two years, accidents of shovels and trucks falling into the goaf have occurred successively, as shown in Figures 2(a) and (2b). Therefore, in order to avoid accidents and realize safe mining, it is necessary to conduct the comprehensive exploration of the goafs (mined-out areas) distributed within the boundary of the open-pit coal mine. It also provides basic data and information for the stability evaluation and effective control of the proven goaf and water accumulation areas.

According to the geological data collected in the past and the urgency of solving problems, the research area of this paper is divided into two parts. As shown in Figure 3, the area of exploration area $A$ is $0.26 \mathrm{~km}^{2}$, the area of exploration area $B$ is $0.11 \mathrm{~km}^{2}$, and the total area is about $0.37 \mathrm{~km}^{2}$.

pi In recent years, unmanned aerial vehicle (UAV) surveying and mapping technology has gradually become the main tool of surveying and mapping due to its advantages of automation, intelligence, low cost, and high precision. The UAV aerial survey is used to accurately acquire the three-dimensional model of the slope in the key area of Yuanbaoshan open-pit coal mine, which provides basic information for the real-time visualization of the open-pit mine and the establishment of the engineering geological research profile. Some aerial survey results of UAV are shown in Figure 4. The aerial survey results show that the surface elevation of the open-pit mining area is $+472 \mathrm{~m}$ to $+490 \mathrm{~m}$. The topographic relief patterns of the two exploration areas are shown in Figure 5.

2.2. Geophysical Characteristics. In order to avoid the multisolution of the single geophysical exploration method, 


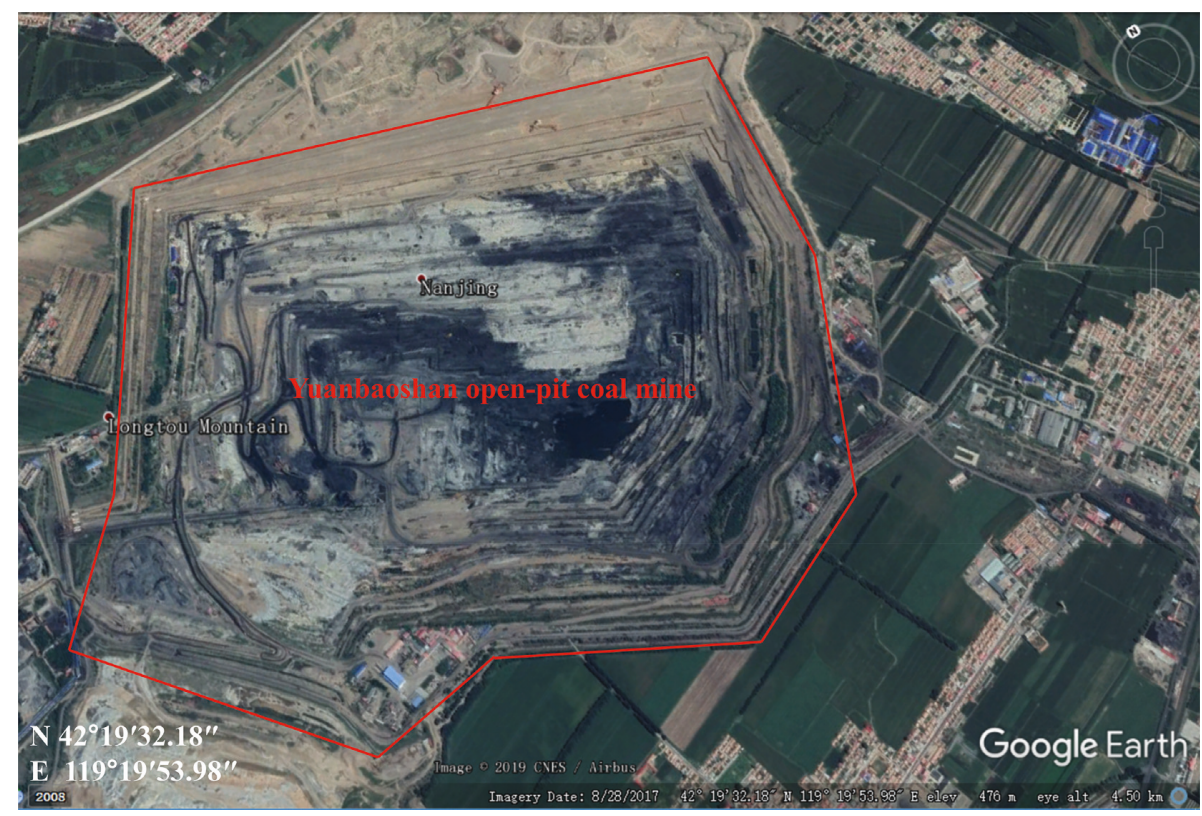

FIGURE 1: Location of Yuanbaoshan open-pit coal mine.

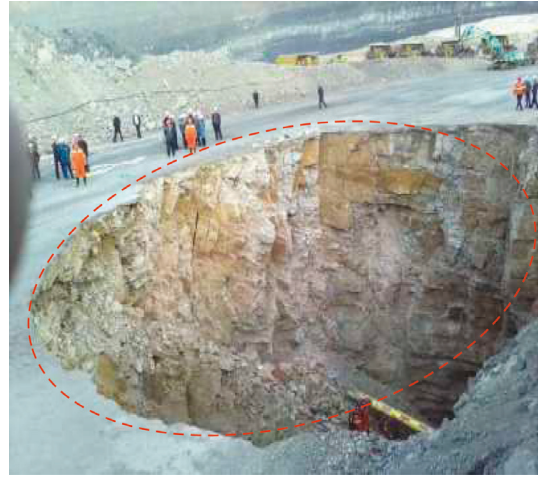

(a)

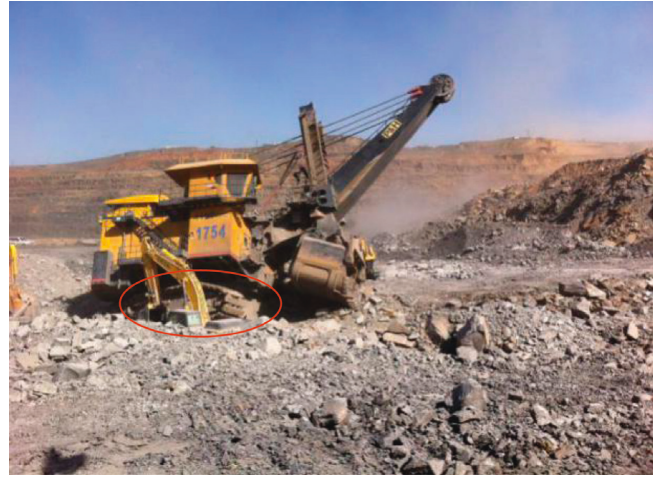

(b)

Figure 2: Safety accident scene in the open-pit mine due to underground goaf. (a) Due to the insufficient safety thickness of the roof of unknown goaf, heavy truck fell into the underground goaf $30 \mathrm{~m}$ deep. (b) During the mining process of the open-pit coal mine, the track on the right side of shovel fell into the collapsed underground goaf.

improve the accuracy of exploration, and have a qualitative understanding of the geophysical characteristics of the exploration area, the resistivity logging method [24, 25] is used to study the resistivity distribution law of different depth strata in the exploration area. The column diagram of the resistivity logging method in exploration area $B$ is shown in Figure 6. It can be seen that shallow strata over $-70 \mathrm{~m}$ present high resistivity characteristics. The strata near $-70 \mathrm{~m}$ to $-180 \mathrm{~m}$ in the middle of the column diagram are characterized by low resistivity. About $-180 \mathrm{~m}$ to $-380 \mathrm{~m}$ is the reflection of coal-bearing strata, showing high resistivity. The deep strata below $-380 \mathrm{~m}$ are interbedded with medium and fine sandstones, showing low resistivity as a whole. In summary, the strata in the exploration area show the electrical characteristics of "high resistivity to low resistivity to high resistivity to low resistivity" from shallow to deep vertically.

\section{Comprehensive Geophysical Prospecting Method}

3.1. Transient Electromagnetic Method. The transient electromagnetic method (TEM) belongs to the time-domain electromagnetic induction method. Before 1990s, it was mainly used to search for metal deposits, coalfields, petroleum, gas, and other fields. Its basic principle is to send a pulse magnetic field (or electric field) to the underground by using an ungrounded loop (or a couple source), that is, to send a current pulse square wave on the transmitting loop, and the square wave will dropinstantaneously. Generate a magnetic field that can propagate underground. Under the excitation of the primary magnetic field, the geological body will produce eddy current, whose size depends on the conductivity of the geological body. After primary magnetic field disappears, the eddy current can not disappear 


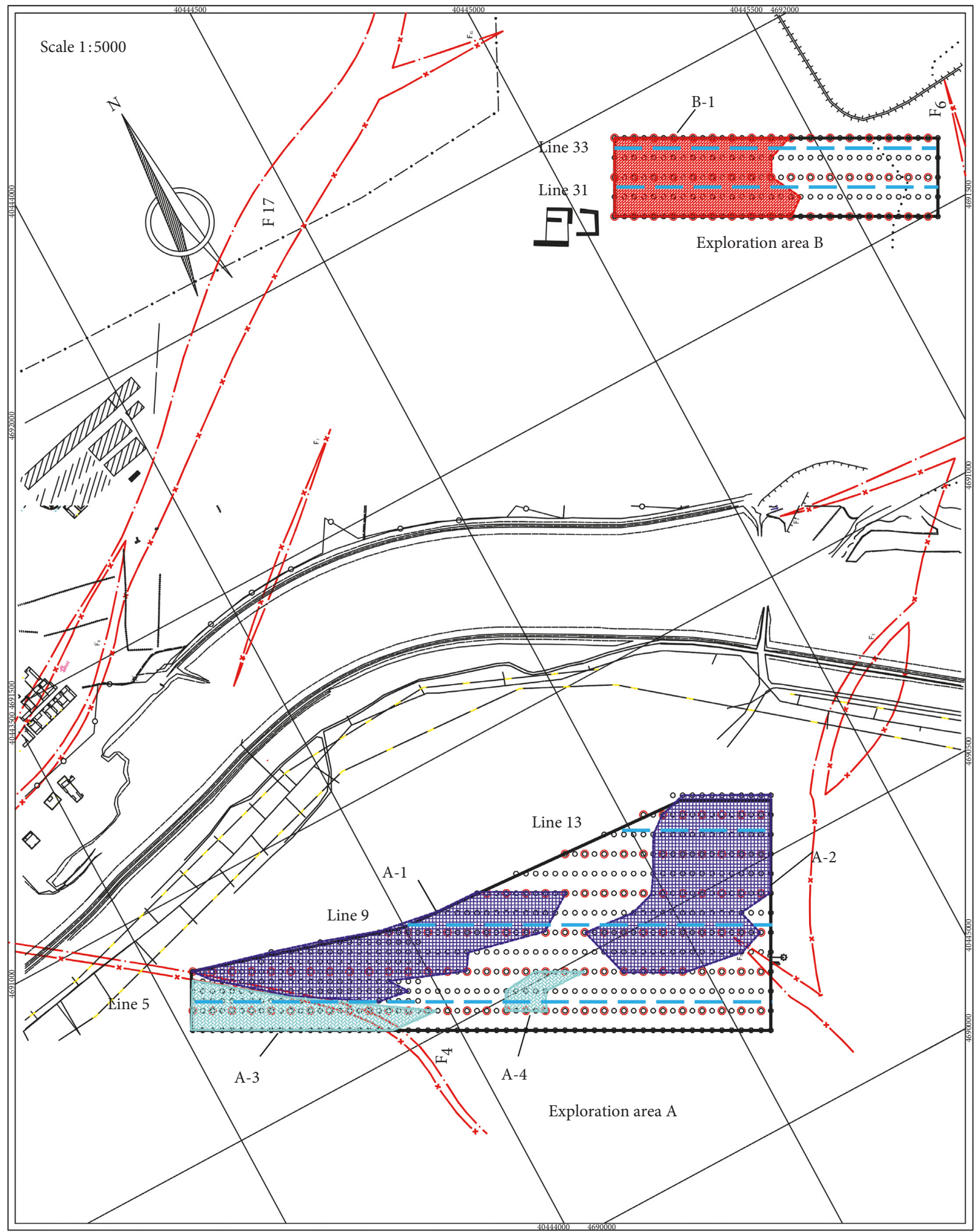

A-1: Inferred of goaf with water accumulation

A-2: Inferred of goaf with water accumulation

A-4: Inferred of water-rich fracture zone

A-3: Inferred of water-rich fracture zone

B-1: Inferred of goaf with water accumulation

Figure 3: Zoning map of the comprehensive geophysical prospecting study area. 


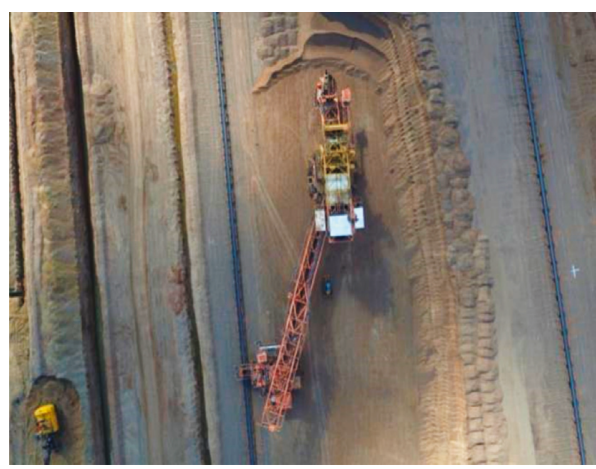

(a)

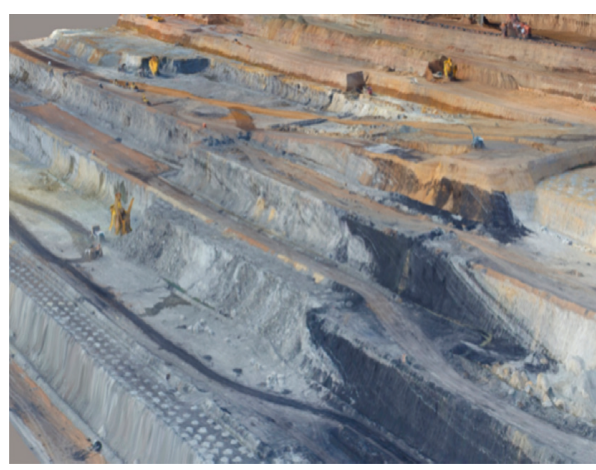

(c)

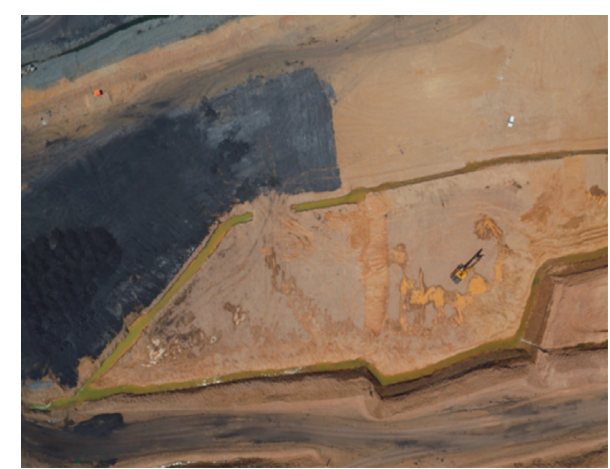

(b)

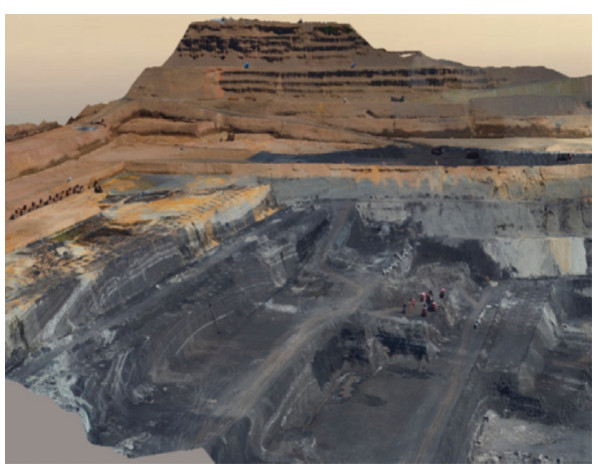

(d)

FIgURE 4: Aerial survey achievements of unmanned aerial vehicles. (a) Top view of the working area of the bucket-wheel excavator. (b) Top view of the eastern area of the working slope. (c) Three-dimensional model of the surface local area in the middle part of the working slope. (d) Three-dimensional surface model of the eastern area of the working slope.

immediately. It will have an excessive process (attenuation process), which produces attenuated secondary magnetic field to propagate to the surface. The secondary magnetic field will be received by the receiving line or magnetic probe of the surface instrument. The variation of the secondary magnetic field will reflect the electrical distribution of underground geological bodies. Secondary induction electromotive force (SIEMF) is measured with different delay times in the receiver, so the attenuation characteristics of the secondary magnetic field with time are obtained. The pseudosection map of resistivity inversion can be obtained by calculating program, and then the geological condition of deep underground can be judged. The advantages of TEM are easy handling, strong adaptability to surface sites, and high efficiency [20].

3.2. Controlled Source Audio-Frequency Magnetotellurics. For a long time, people can use various exploration methods to solve the engineering geology and hydrogeology problems concerned about the shallow surface geology of the engineering area, but there has been a lack of effective methods to understand the deep geological conditions. In geophysical exploration, electrical prospecting has been paid attention to because of its variability of field sources and effectiveness of methods. Controlled source audio-frequency magnetotellurics (CSAMT) is a new electrical method developed in the late 1980s [26]. Based on electromagnetic wave propagation theory and Maxwell equations, Cagniard's apparent resistivity $[27,28]$ equation is derived as follows:

$$
\rho_{\mathrm{aC}}=\frac{1}{\mu \omega}\left|\frac{E_{x}}{H_{y}}\right|^{2},
$$

where $E$ and $H$ are the orthogonal electric and magnetic fields, respectively. $\omega$ and $\mu$ denote angular frequency and magnetic permeability. If the electric field is measured in millivolt $/ \mathrm{km}$ and magnetic field is measured in $\mathrm{nT}$ (nanotesla), the above equation becomes

$$
\rho_{\mathrm{aC}}=\frac{1}{5 f}\left|\frac{E_{x}}{H_{y}}\right|^{2} .
$$

According to the skin effect theory of the electromagnetic wave, the formula of skin depth can be derived as follows:

$$
\delta=\sqrt{\frac{2}{\omega \mu \sigma}}=503 \sqrt{\frac{\rho}{f}},
$$

where $\rho$ is the electrical resistivity and $f$ is the frequency.

It has been shown that when the surface resistivity is fixed, the propagation depth (or detection depth) of the electromagnetic wave is inversely proportional to the frequency. In high frequency, the detection depth is shallow; in low frequency, the detection depth is deep. Therefore, the 


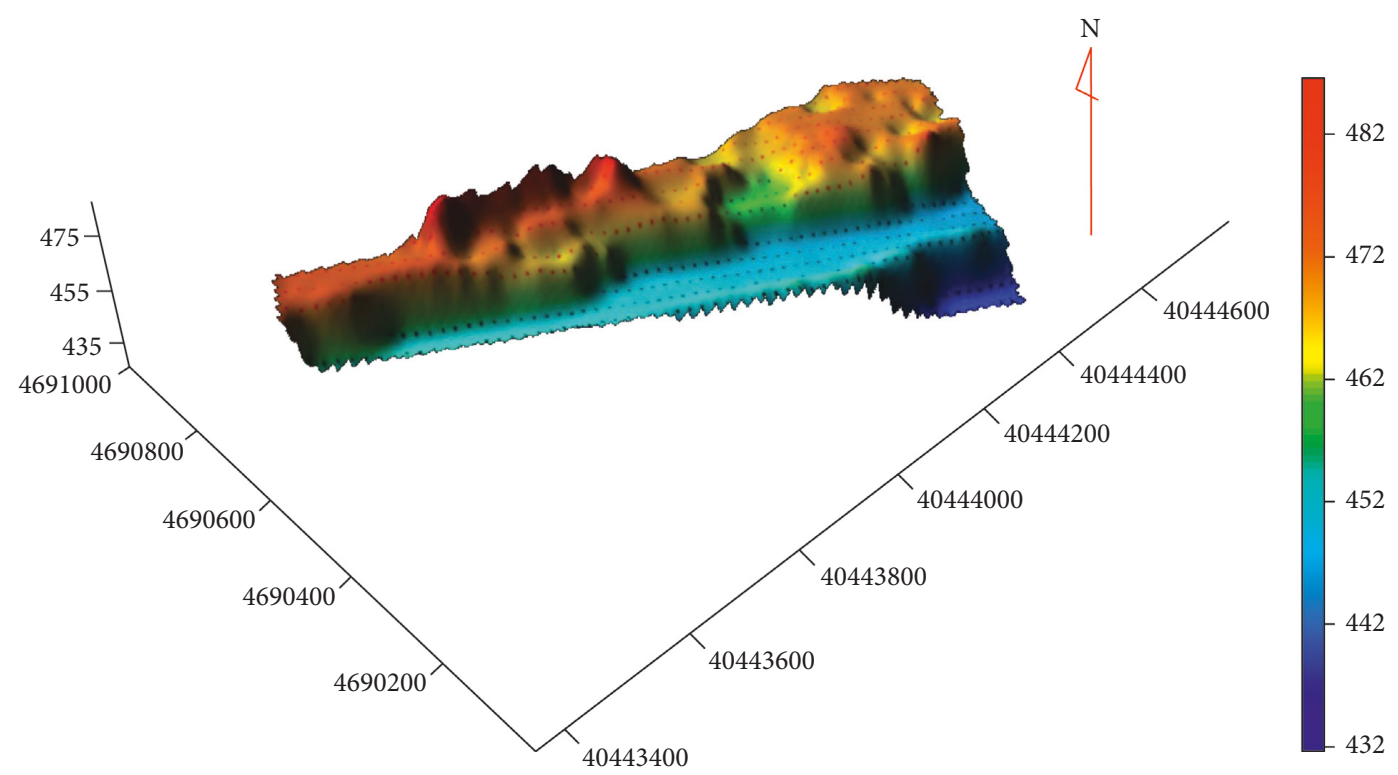

(a)

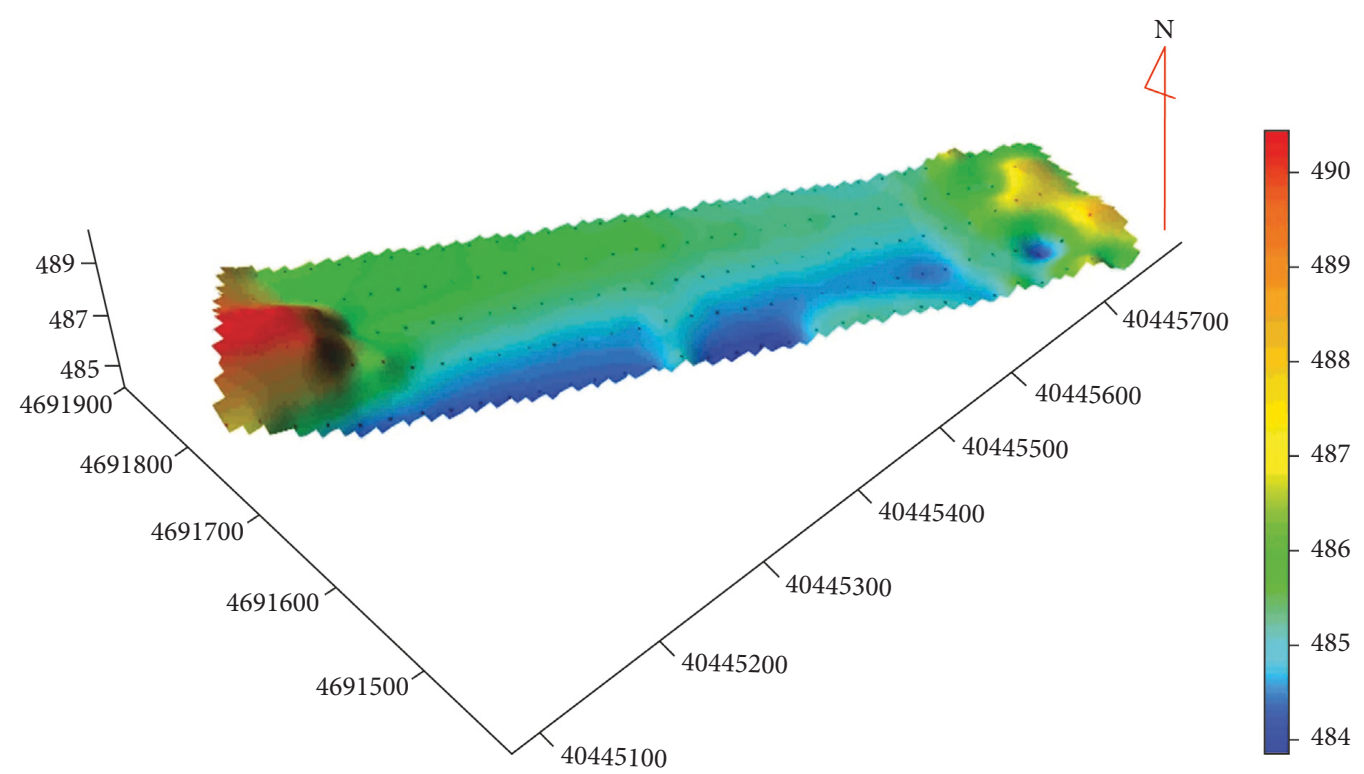

(b)

Figure 5: Surface topographic map of exploration area. (a) Topography of exploration area A. (b) Topography of exploration area B.

detection depth can be changed by adjusting the transmission frequency to achieve the purpose of detection.

The general principle of the CSAMT method is to use controllable artificial field source and measure the Cagniard's apparent resistivity by the ratio of electric field to magnetic field. At the same time, based on the principle of skin depth of the electromagnetic wave, electrical sounding of different depths is carried out by changing frequency. Therefore, the CSAMT method has the following advantages in its work: it is suitable for various sites, high efficiency, and can receive seven electric fields $E$ and one magnetic field $H$ at the same time in a single launch; it has strong anti-interference ability; it has a large exploration depth range, up to $1,000 \mathrm{~m}$; it can detect the resistivity discrepancies in the geological background, has small high-resistance shielding effect, and can penetrate highresistance strata. It is precisely because of these advantages that it was rapidly popularized and applied in engineering survey all over the world in the late 1990s.

V8 multifunctional electromagnetic prospecting system is used, and the main technical parameters of the instrument are as follows: input impedance $>100 \mathrm{M} \Omega$, compensation error $<0.12 \%$, resolution: $1 \mu \mathrm{V}$, power: $2800 \mathrm{~W}$, maximum output current: $40 \mathrm{~A}$, and maximum supply voltage: $140 \mathrm{~V}$.

3.3. Data Processing Method. The data collected on site must be further processed before they can be transformed 


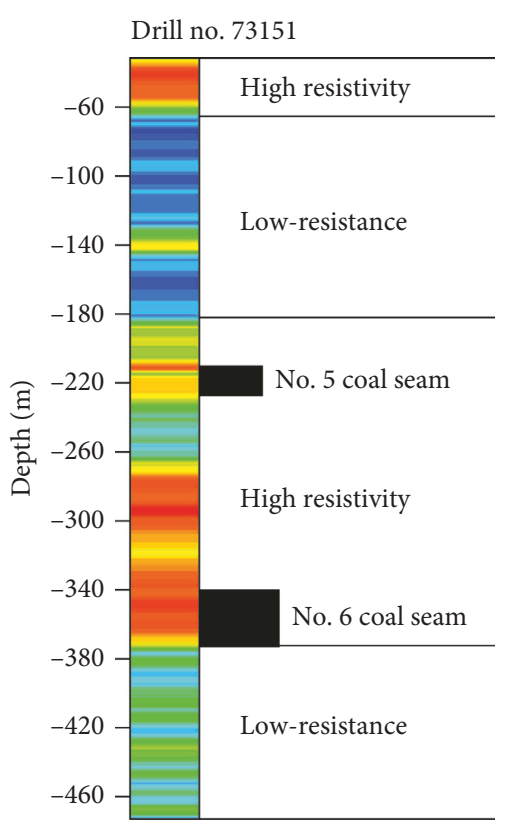

FIGURE 6: Column diagram of borehole resistivity in exploration area B.

into the required geophysical and geological results. The main parameters of TEM field observation are sampling time, emission current, and normalized induction secondary field, etc. Data processing begins with preprocessing, that is, data cataloguing, quality inspection, rejection of unqualified data, data quality statistics and classification, and sorting out the sequence and format required for special software. Secondly, the data are filtered to remove the suppressed interference signals and restore the original characteristics of geological signals. Then, the parameters are converted; that is, the apparent resistivity and apparent depth are obtained by software conversion. On this basis, topographic correction and other processing are done according to survey, geology, and drilling data. Finally, various sectional diagrams are drawn for data analysis.

There are large bucket excavator system and material conveying tape in exploration area A. Its working voltage is about $6000 \mathrm{v}$, which makes the data near the operation area subject to certain electromagnetic interference. In addition, other large-scale operation vehicles in the exploration area will also have a certain impact on data acquisition. The data affected by electromagnetic interference will have abrupt maximum or minimum values, and even the phenomenon of local data uplifts or decreases. Figure 7 is the contrast chart of the single-point quadratic field attenuation curve in double logarithmic coordinates. The attenuation curve without electromagnetic interference tends to decay in turn, and the data points basically do not show sudden change. The first part of the attenuation curve of the quadratic field of the measured point under electromagnetic interference basically maintains the trend of attenuation in turn. However, after $5 \mathrm{~ms}$, the data show obvious "jitter and jump" phenomenon and the original attenuation law is broken.
Correction is needed for the disturbed data. Hundreds of sampling points were extracted, and the interfered data were processed by combining the method of limit difference, fitting, and multipoint smoothness. The comparison of resistivity sections before and after processing is shown in Figure 8 , in which Figure $8(\mathrm{a})$ is the apparent resistivity section of data subject to electromagnetic interference and Figure $8(\mathrm{~b})$ is the apparent resistivity section after interference correction. After correction, the change rule of affected data is consistent with that of data not subject to electromagnetic interference.

The measured TEM data are the comprehensive reflection of the underground electrical layers. Vertically, the original curve or the original apparent resistivity section can only show the comprehensive electrical change trend of several sets of strata. To interpret the distribution of the real strata or the closest to the real strata and geological anomalies through the measured data, the data should be inverted to obtain the subsurface resistivity distribution.

Figure 9 shows the different data processing methods for transient electromagnetic exploration. From Section 2.2, it can be seen that the strata in the exploration area present the electrical law of "high-low-high-low" from shallow to deep. By comparing (a) and (b) in Figure 9, it can be concluded that the section formed by inversion results reflects the electrical property law of the formation from shallow to deep "low-high-low-high," while the section of the late formula shows the change characteristic of "high-low" from shallow to deep, which is not consistent with the actual electrical property of the formation. In addition, although the late formula has the advantages of simplicity and rapidity, the algorithm is suitable for the late time. There is some distortion in the early calculation, which results in unreal high resistivity response in the shallow section, and the inversion calculation restores the actual electrical property of the formation. Therefore, the inversion method is chosen as the data processing method of TEM exploration.

The data processing flow of controlled source audiofrequency magnetotellurics (CSAMT) is shown in Figure 10. Detailed data processing can be referred to [26-28].

3.4. Results of Integrated Geophysical Prospecting. By using the integrated geophysical prospecting method (TEM and CSAMT), the mined-out area and water accumulation area of 6 coal seams in the exploration area were comprehensively explored. If the stratum is not affected by the goaf or the water-conducting structure, the resistivity of coal-bearing stratum changes orderly, and the isoline changes steadily in the resistivity section, showing a layered distribution. When there is a goaf water accumulation area or water-conducting structure, the resistivity of anomalous areas decreases, and the isoline distribution is distorted, deformed, or densely striped. Typical results for exploration areas A and B are shown in Figures 11-15, respectively. The location of the selected exploration line is shown in Figure 3.

Figure 11 shows the resistivity sections of line 5 obtained by different methods. The survey line is located in the southern boundary of the exploration area. The length of the 

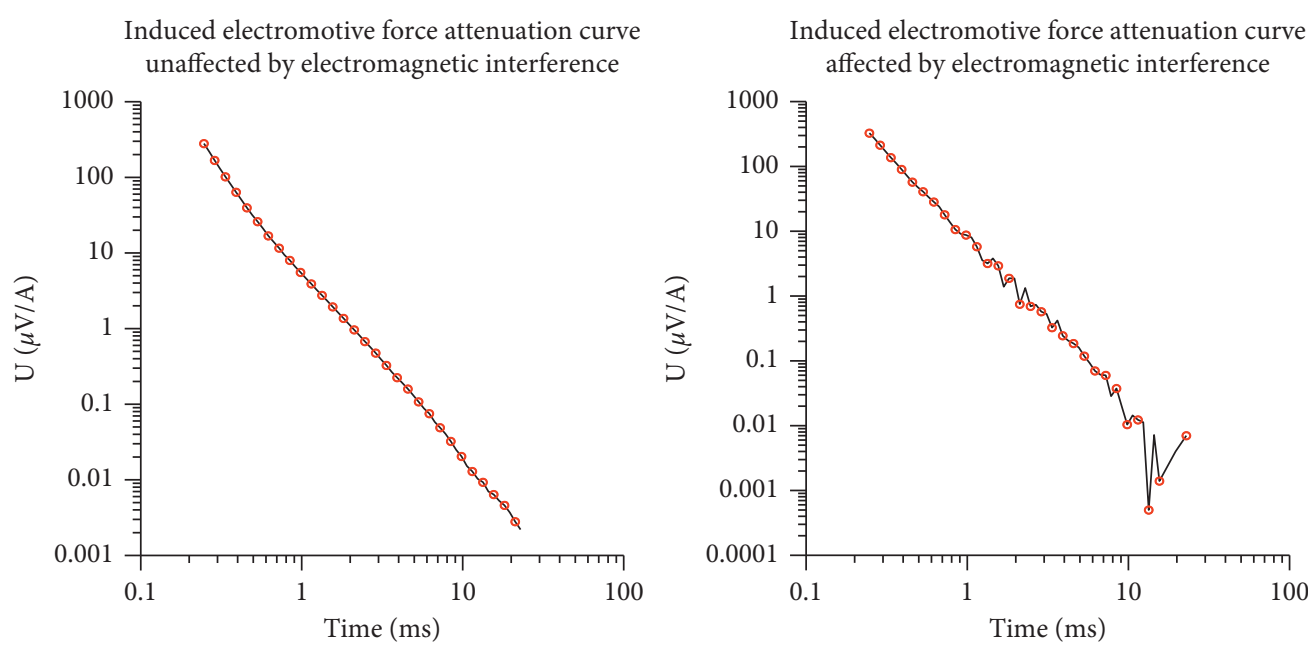

FIGURE 7: Comparison of single-point attenuation curves of transient electromagnetic interference.

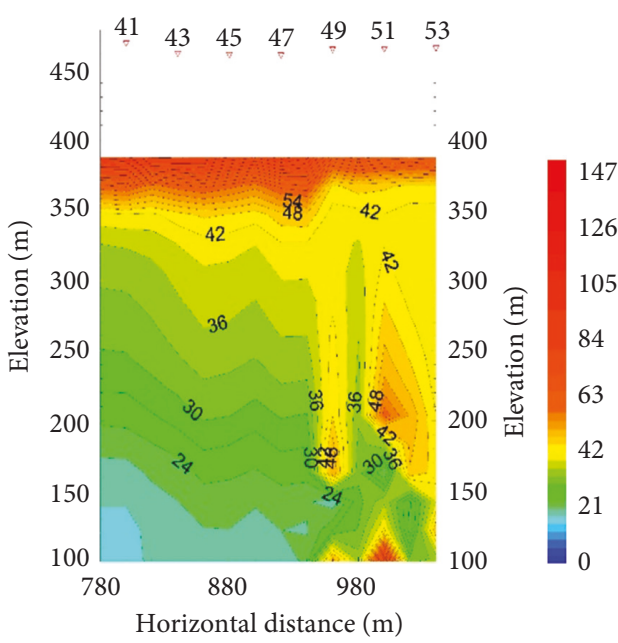

(a)

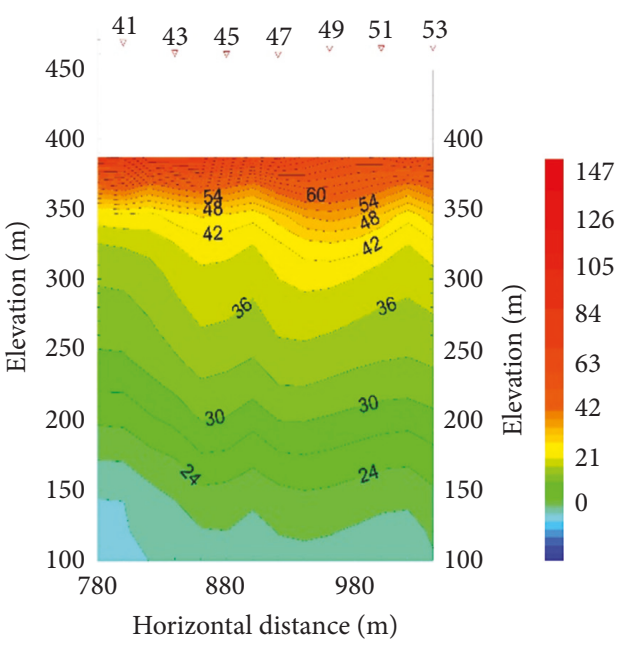

(b)

Figure 8: Comparison of pseudosection of resistivity (a) before and (b) after interference correction.

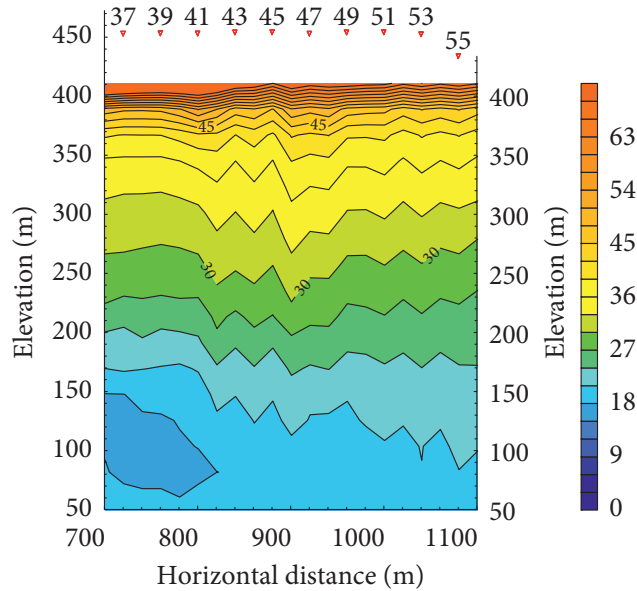

(a)

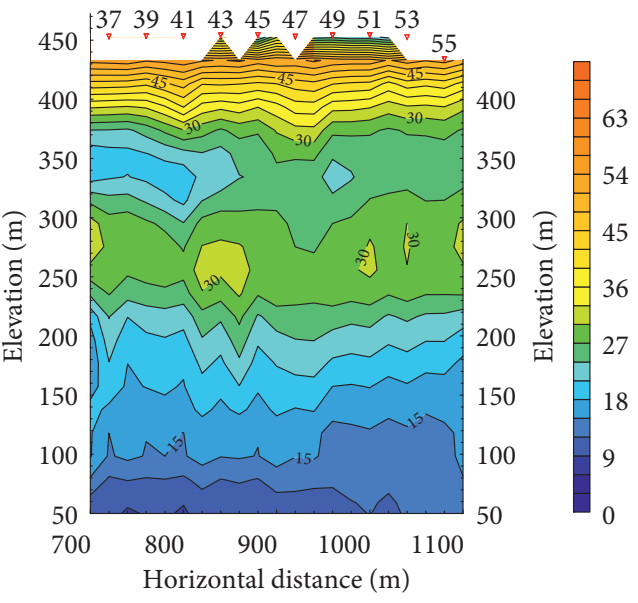

(b)

FiguRE 9: Different data processing methods for transient electromagnetic exploration. (a) Late formula for calculating the resistivity section. (b) Inversion method for calculating the resistivity section. 


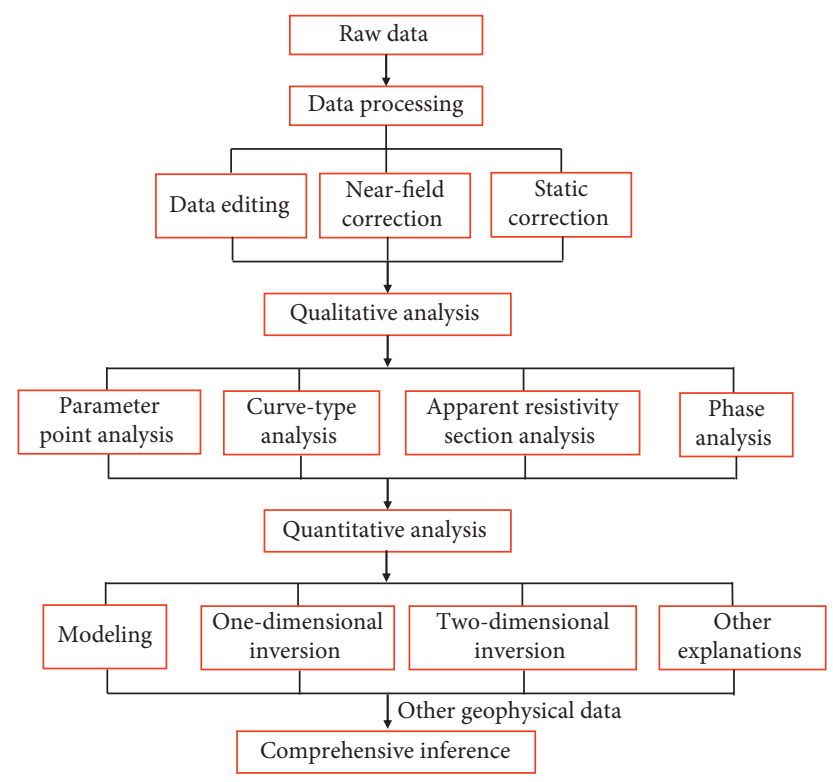

FIGURE 10: Data processing flow chart of the CSAMT method.

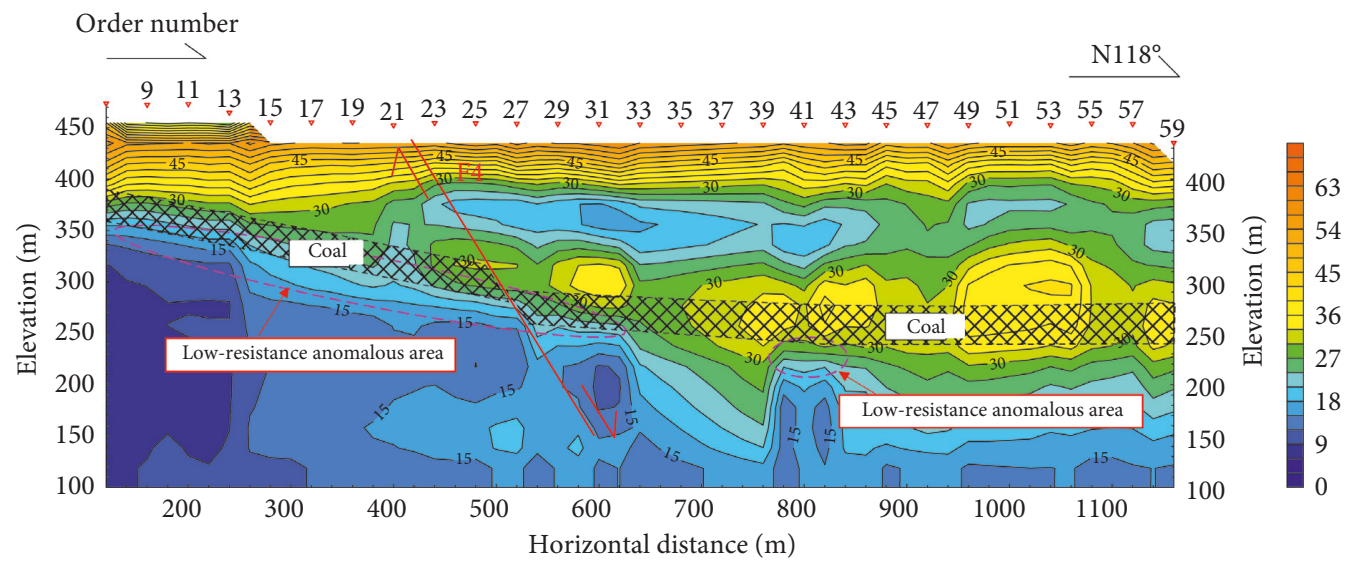

(a)

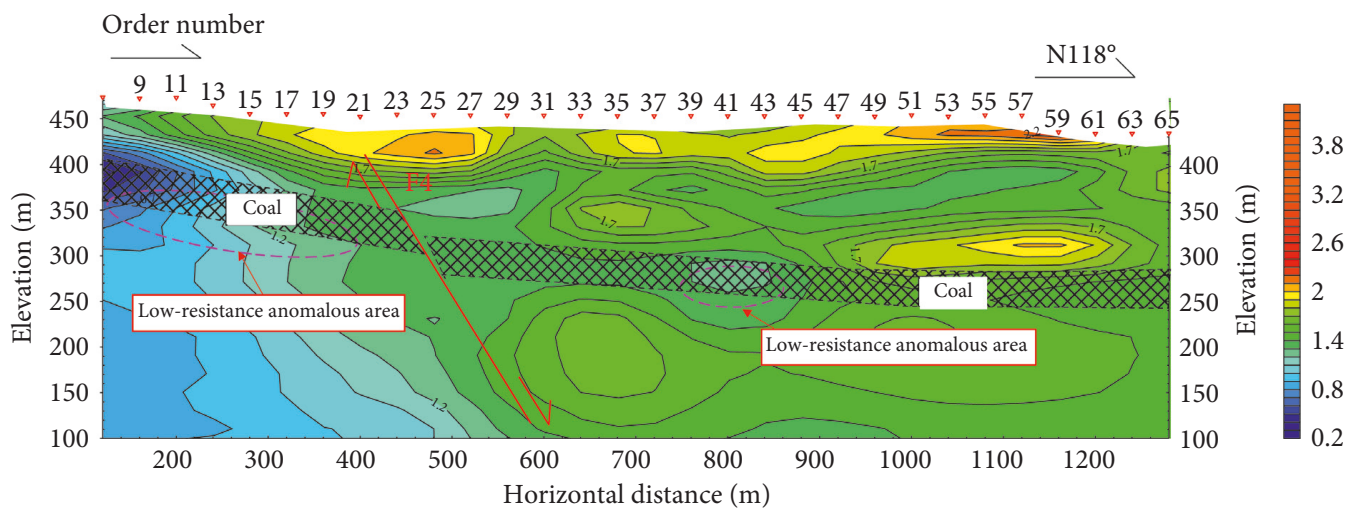

(b)

FIGURE 11: Resistivity sections obtained by different methods. (a) Inversion of the resistivity profile from line 5 of the TEM method. (b) Inversion of the resistivity profile from line 5 of the CSAMT method.

survey line is $1180 \mathrm{~m}$, and the surface roughly flat. Coal seams gradually deepen from west to east. It can be seen that the vertical resistivity of strata in the range of exploration depth generally shows the trend of "high resistivity-low resistivity-high resistivity-low resistivity," which coincides with the electrical characteristics of the actual stratum described in Section 2.2. The horizontal resistivity isoline of strata near the coal seam is obviously distorted between 


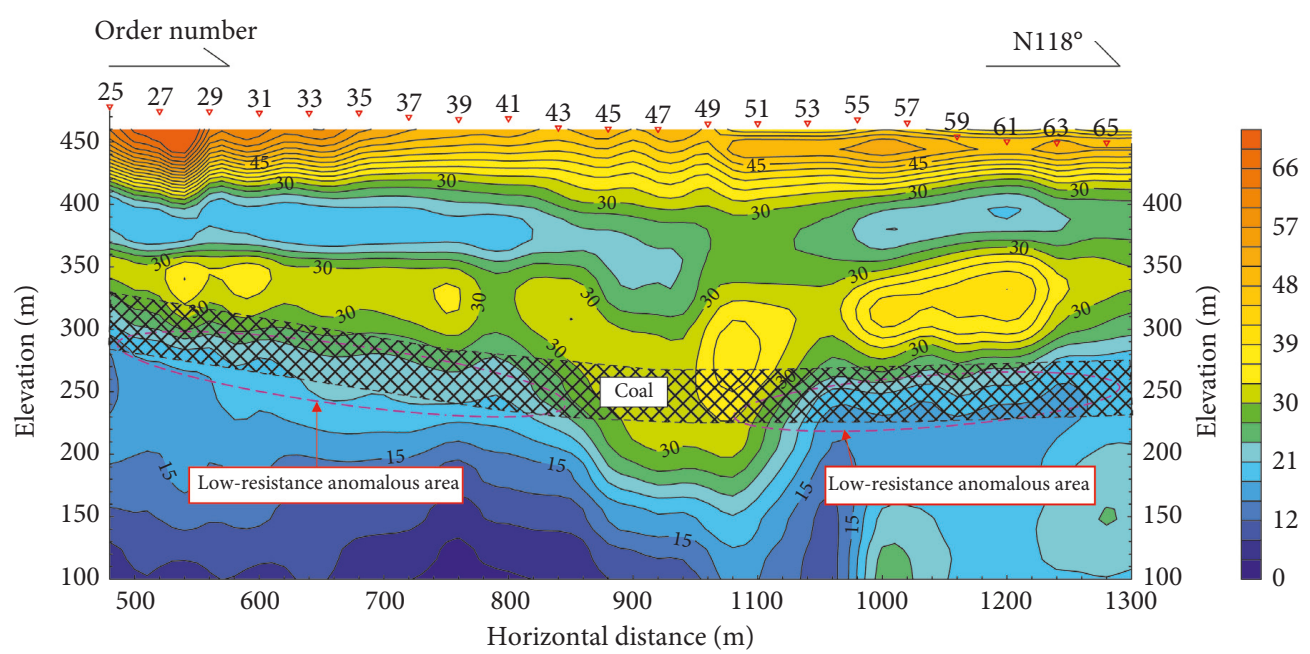

(a)

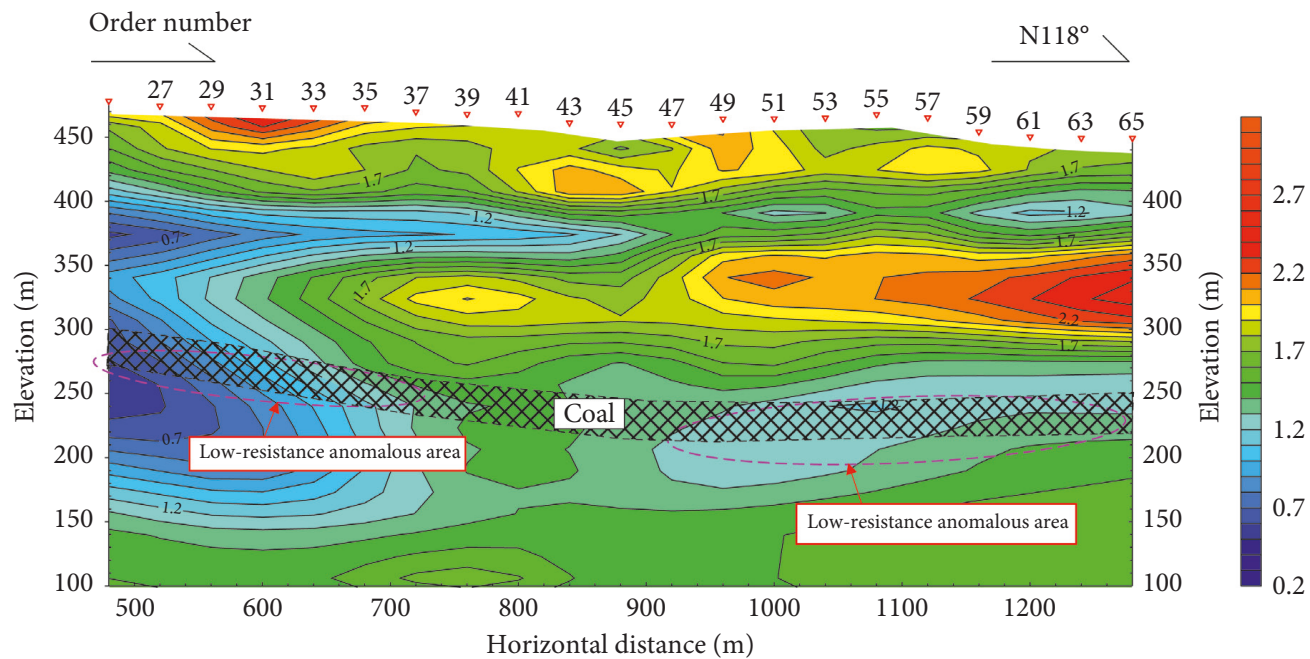

(b)

FIGURE 12: Resistivity sections obtained by different methods. (a) Inversion of the resistivity profile from line 9 of the TEM method. (b) Inversion of the resistivity profile from line 9 of the CSAMT method.

No. 7 and No. 33 survey point, showing obvious characteristics of low-resistance anomaly. In addition, there is a normal fault F4 near No. 27 survey point. The fault distance is $30 \mathrm{~m}$, which is not suitable for mining. Therefore, the anomaly can be inferred as a fractured water-rich zone. The horizontal resistivity isoline of strata near the coal seam is obviously distorted between No. 39 and No. 43 survey point, also showing obvious characteristics of low-resistance anomaly. As shown in Figure 11(b), the inversion resistivity profile obtained by the CSAMT method is basically consistent with that obtained by the TEM method. It is also shown that the electrical characteristics and the resistivity anomalies delineated by both methods are in agreement.

Figure 12 shows the resistivity sections of line 9 obtained by different methods. The survey line is located in the middle of exploration area A. The length of the survey line is $840 \mathrm{~m}$, and the topography is relatively flat. The coal seam is gradually deepening from west to east from No. 25 to No. 47, and the whole coal seam is slightly uplifted from No. 48 to
No. 66. From Figure 12(a), it can be seen that the vertical resistivity of the stratum in the exploration depth generally shows a trend of "high resistivity to low resistivity to high resistivity to low resistivity," which coincides with the electrical characteristics of the actual stratum described in Section 2.2. The cross-sectional map is bounded by No. 50 survey point, and the rise and fall of the target electrical layer are obvious. From the trend of the coal seam, the trend of the left isoline is basically consistent with the trend of the actual stratum. Laterally, between No. 25 and No. 43 survey point, the resistivity isoline of the seam near the No. 6 coal seam is obviously distorted, showing obvious characteristics of low resistivity anomaly (the magenta ellipse in the picture). It is inferred that the low-resistance anomaly may be related to water accumulation in goaf formed by crossborder mining of 6 coals in adjacent coal mines. The isoline on the right side of the section (i.e., between the 50-63 survey points) changes obviously, the vertical high resistivity layer rises obviously upward, and the lower part of the section shows obvious 


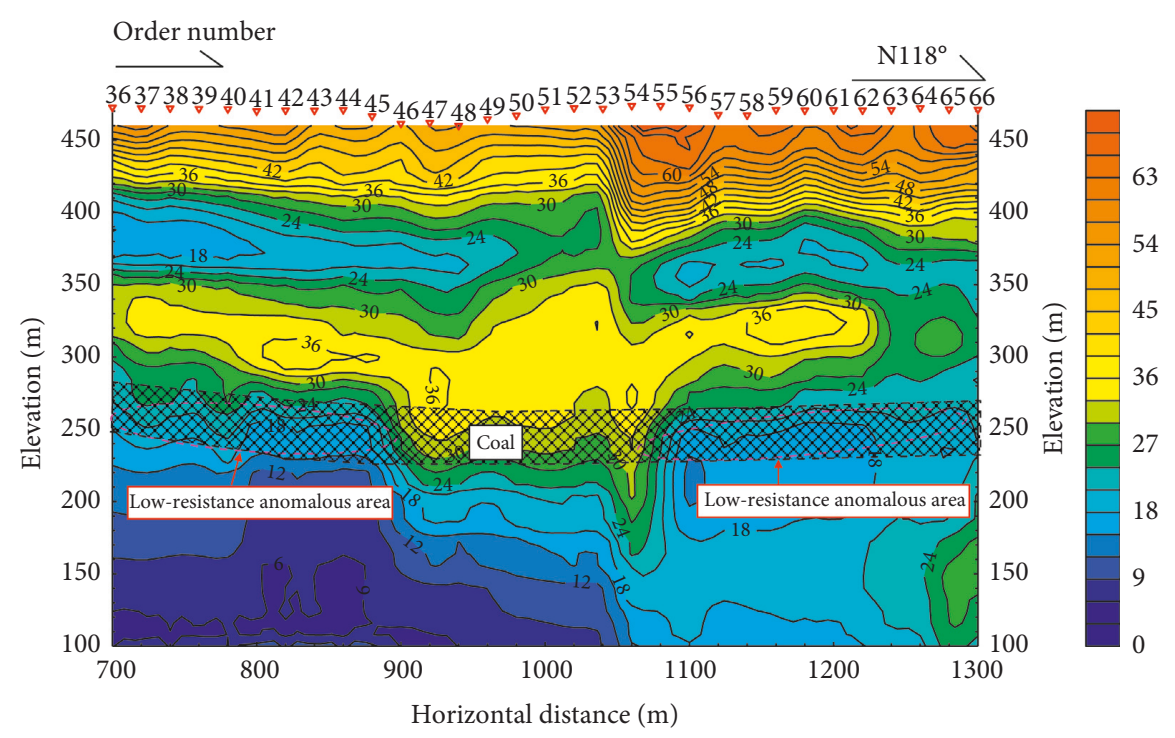

(a)

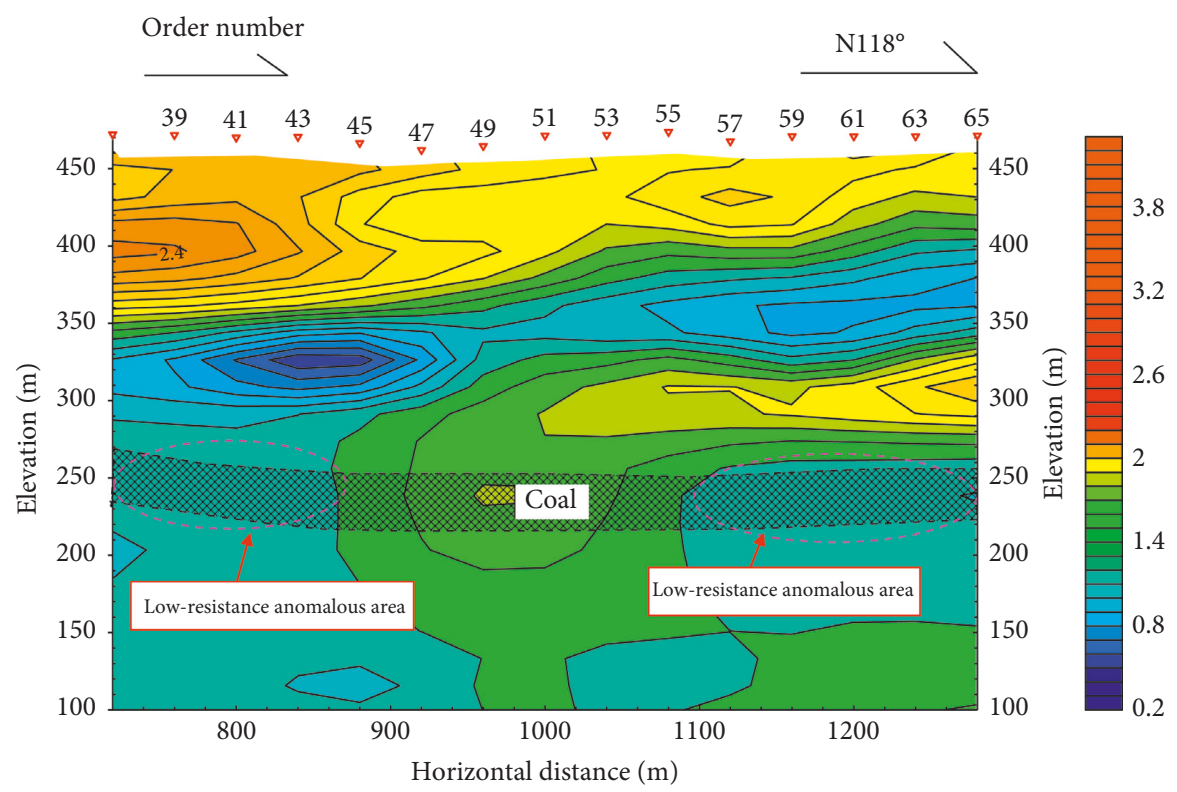

(b)

FIGURE 13: Resistivity sections obtained by different methods. (a) Inversion of the resistivity profile from line 13 of the TEM method. (b) Inversion of the resistivity profile from line 13 of the CSAMT method.

low-resistance anomaly. It is inferred that it is the electrical reflection of No. 6 coal mined out and accumulated water. The upper high-resistance anomaly is similar to the electrical reflection of the nonfilling cracks formed by the caving of overlying strata after coal mining. As shown in Figure 12(b), the inversion resistivity profile obtained by the CSAMT method is basically consistent with that obtained by the TEM method.

Figure 13 shows the resistivity sections of line $13 \mathrm{ob}-$ tained by different methods. The survey line is located in the north of exploration area A. The length of the survey line is $720 \mathrm{~m}$. The surface is nearly flat, and the undulation is small. From Figure 13(a), it can be seen that the vertical resistivity of the strata in the exploration depth generally shows a trend of "high resistivity to low resistivity to high resistivity to low resistivity," which is consistent with the electrical characteristics of the actual strata mentioned above. The resistivity isoline of the stratum near the coal seam is obviously distorted and shows obvious low-resistance anomaly between No. 36 and No. 46 as well as between No. 54 and No. 65 survey point transversely. It is inferred that the low-resistance anomaly may be related to water accumulation in goaf formed by crossborder mining of 6 coals in adjacent coal mines. As shown in Figure 13(b), the inversion resistivity profile obtained by the CSAMT method is basically consistent with that obtained by the TEM method, and the anomalies resistivity variations obtained by both methods are in agreement.

The analysis of comprehensive results of some survey lines in exploration area $\mathrm{A}$ is provided earlier, and integrated 


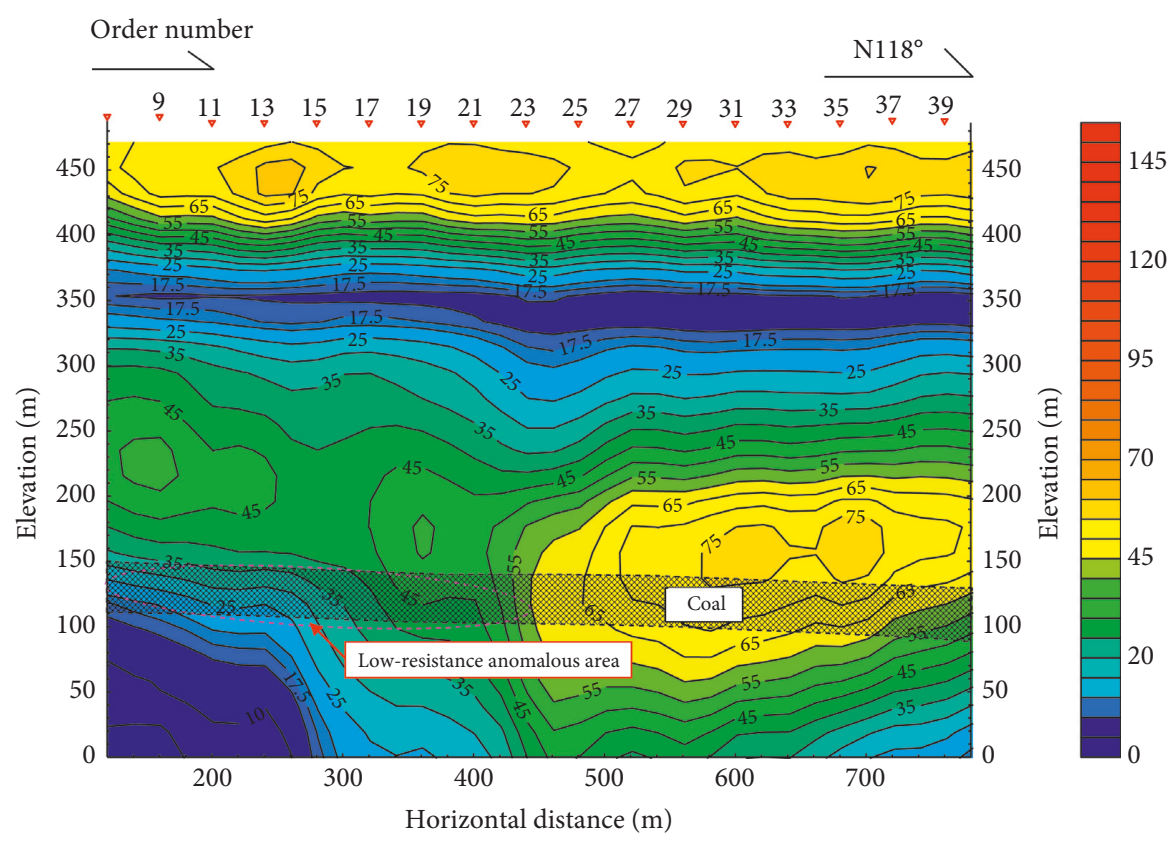

(a)

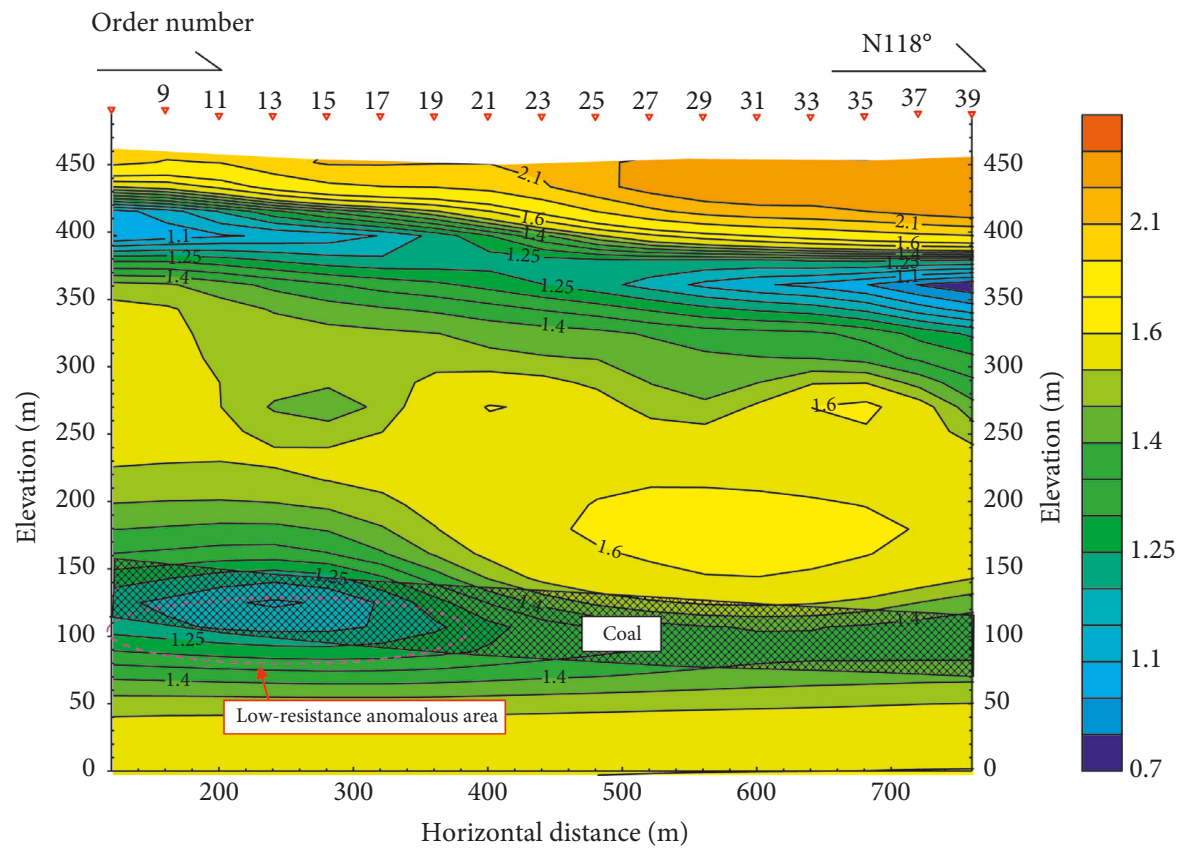

(b)

FIGURE 14: Resistivity sections obtained by different methods. (a) Inversion of the resistivity profile from line 31 of the TEM method. (b) Inversion of resistivity profile from line 31 of CSAMT method.

geophysical exploration techniques are also carried out in exploration area B. Typical results are shown in Figures 14 and 15 . The low resistivity anomalous area near the coal seam can be obtained by comparing the modelling results of the two methods. It can be seen that the electrical characteristics and abnormal reactions obtained by the two geophysical methods are basically consistent. The results of deduced water-filled goaf and water-rich fracture area in exploration areas $\mathrm{A}$ and $\mathrm{B}$ are shown in Figure 3.
3.5. Verification of Borehole Television Method. In order to further verify the position and shape of goaf obtained by the comprehensive geophysical prospecting method, the borehole television method [29] is used to observe the possible goaf in exploration areas A and B. FB580 four-picture borehole television is used for borehole television observation. The borehole television has a high-definition camera in front of the probe and three high-definition cameras in the side of the probe. It can record the situation in the hole in all directions under the condition of water. Borehole 


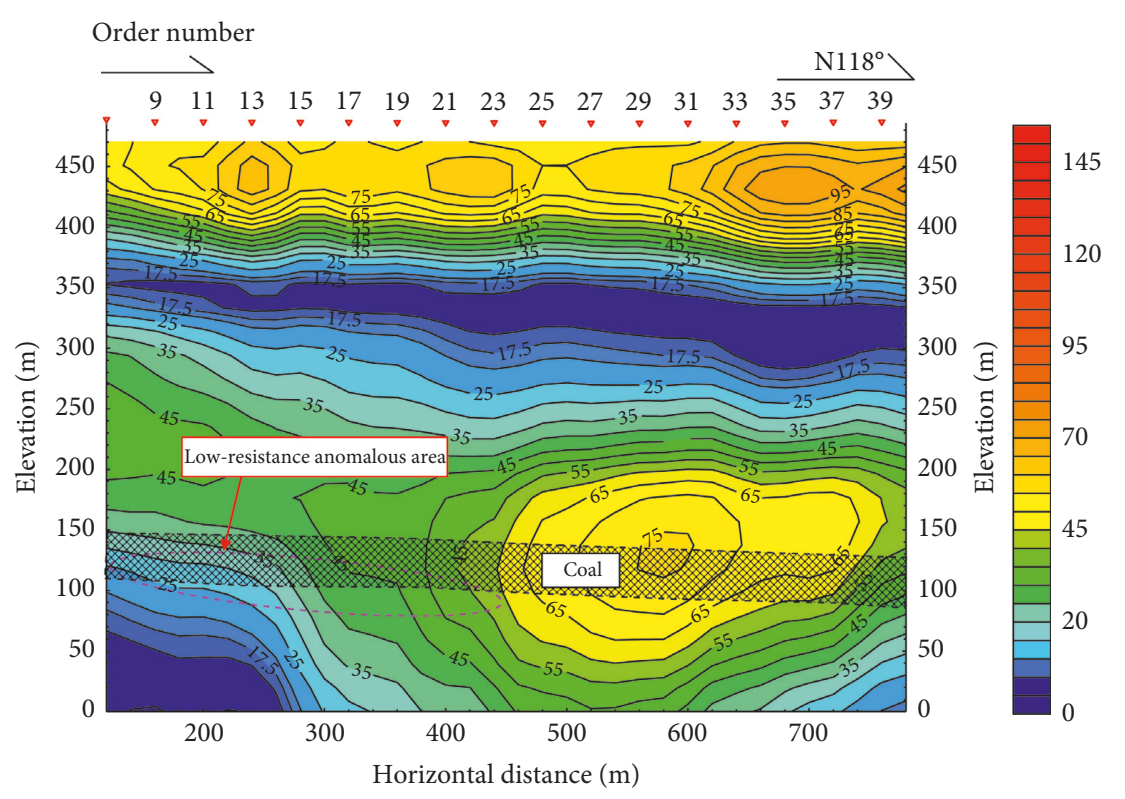

(a)

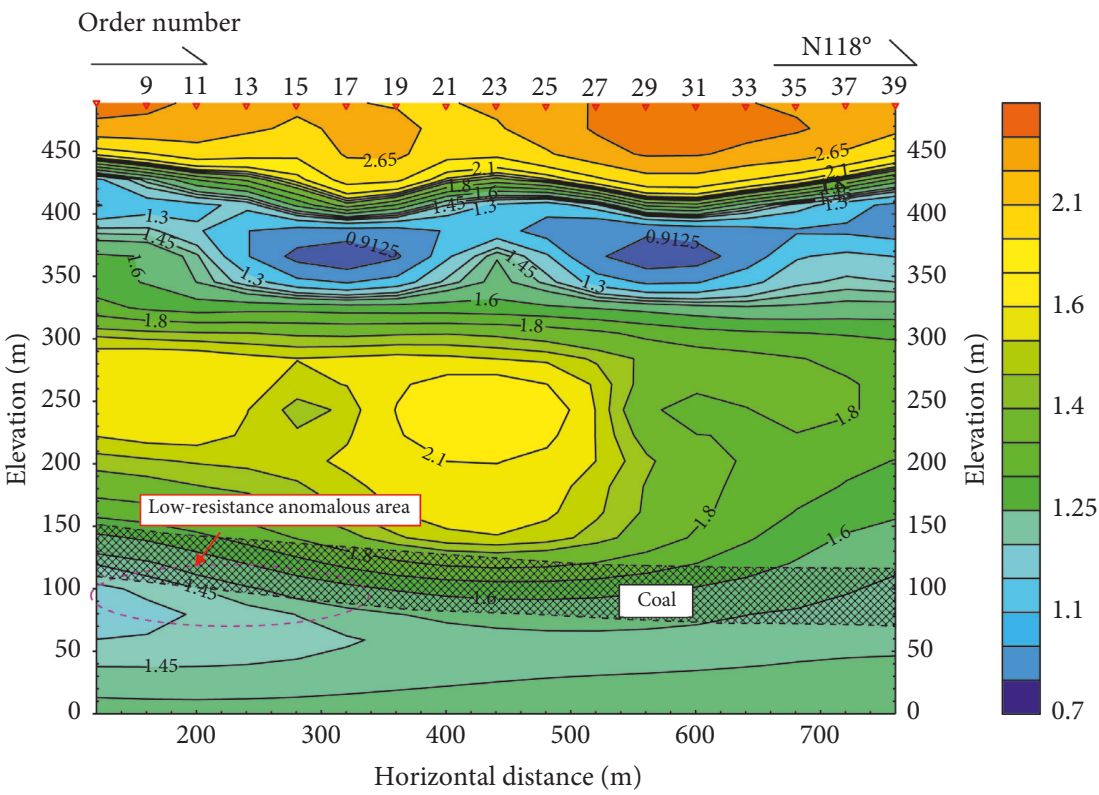

(b)

FIGURE 15: Resistivity sections obtained by different methods. (a) Inversion of the resistivity profile from line 33 of the TEM method. (b) Inversion of the resistivity profile from line 33 of the CSAMT method.

television can also observe the development height of the caving zone and fissure zone above goaf and the water level in the hole. FB580 borehole television and construction site are shown in Figure 16.

Figure 17 shows the television observation results of boreholes in exploration area A. Figure 17(a) is a borehole television image with the probe lowered to a depth of $26.13 \mathrm{~m}$. It can be seen that there is no water in the borehole. Figure 17(b) shows the image of the probe lowered to a depth of $49.83 \mathrm{~m}$. It can be seen that there is water leaking in the hole. Figure $17(\mathrm{c})$ is the image of the probe lowered to a depth of $55.22 \mathrm{~m}$. It can be seen that the water in the hole increases obviously. Figure $17(\mathrm{~d})$ is the image of the probe lowered to a depth of $56.82 \mathrm{~m}$. It can be seen that there is obvious water jet phenomenon in the hole and the water pressure is large. Figure $17(\mathrm{e})$ is the image of the probe lowered to a depth of $92.28 \mathrm{~m}$. The water surface in the hole can be clearly seen. Figure 17(f) is the image of the probe lowered to a depth of $93.49 \mathrm{~m}$. The reflection image of the probe light source on the water surface can be clearly seen. Therefore, the probe depth at this time can be determined as the water level of the goaf, and the water level elevation is $+371.21 \mathrm{~m}$. Figure $17(\mathrm{~g})$ is the image of the probe lowered to a depth of $94.23 \mathrm{~m}$. When the probe enters the water, the 


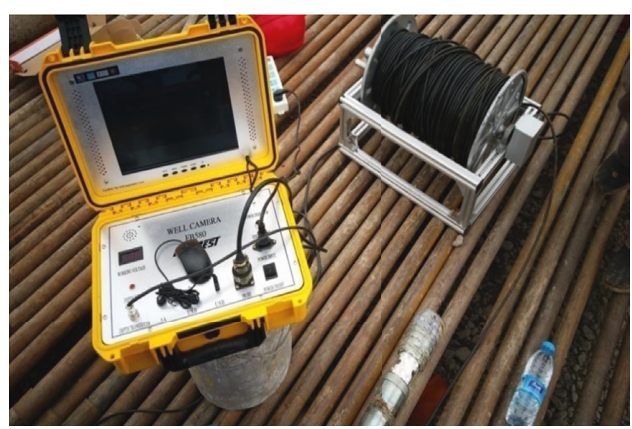

(a)

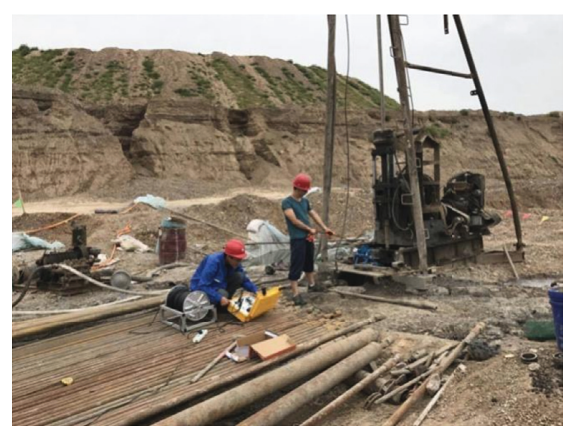

(b)

FIGURE 16: (a) FB580 borehole television; (b) construction site.

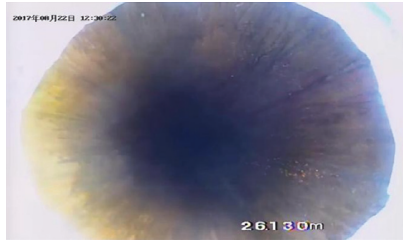

(a)

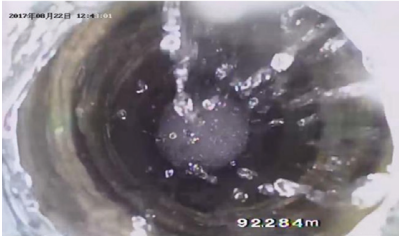

(e)

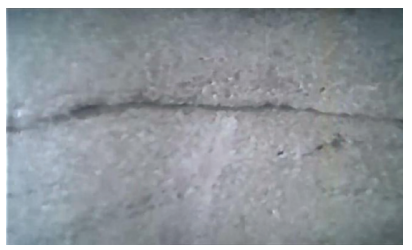

(i)

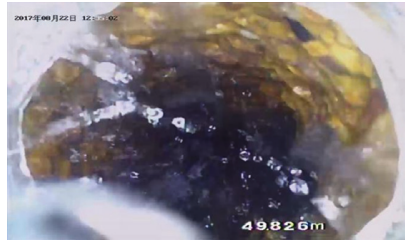

(b)

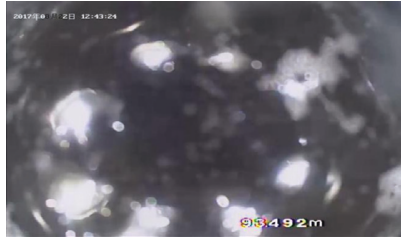

(f)

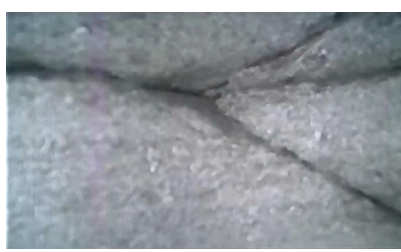

(j)

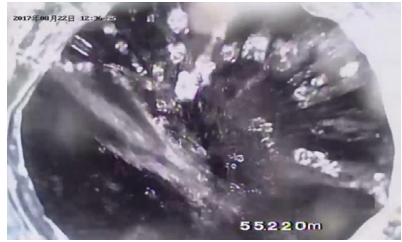

(c)

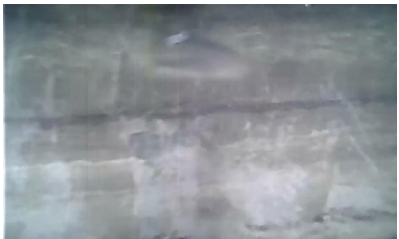

(g)

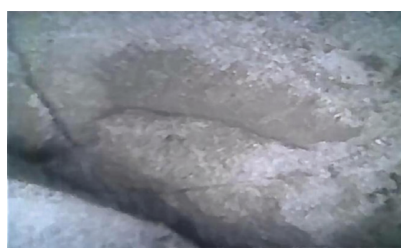

(k)

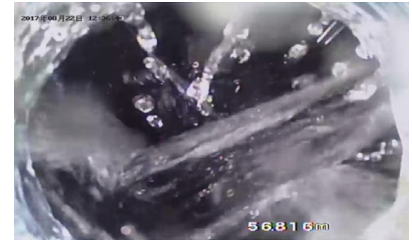

(d)

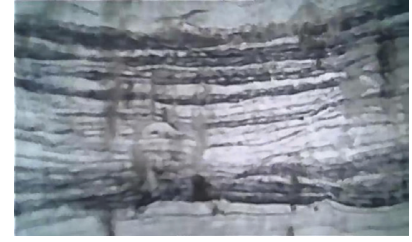

(h)

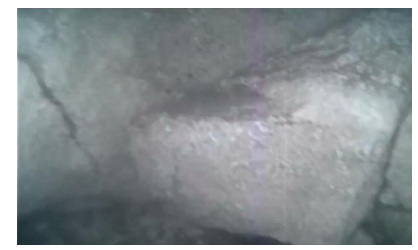

(l)

Figure 17: Television observation results of boreholes in exploration area A.

lateral camera of the probe starts to work, and the bedding surface of the rock mass in the hole wall can be seen. Figure $17(\mathrm{~h})$ is the image of the probe lowered to a depth of $115.54 \mathrm{~m}$. The bedding plane of rock mass in the hole wall can be clearly seen.

Figure 17(i) is an image of the probe lowered to a depth of $130.35 \mathrm{~m}$, with the elevation of $+334.35 \mathrm{~m}$. It is evident that the strata separating fracture can be seen. From the conclusion of borehole television observation in the literature [29], it can been seen that microcracks had been progressively generated in the wall area. The majority of these cracks were not initiated from the preexisting mineral filled joints but appeared at locations where no joints had been present earlier. In addition, the site drilling does not return slurry at this elevation. It is inferred that the location is the upper bound of the water conducting fracture zone above the goaf, and the height of the water conducting fracture zone is about $44 \mathrm{~m}$. Figure $17(\mathrm{j})$ is the image of the probe lowered to a depth of $142.33 \mathrm{~m}$. There are irregular fractures in the rock strata of the borehole. Figure $17(\mathrm{k})$ is an image of the probe lowered to a depth of $156.16 \mathrm{~m}$, with the elevation of $+308.54 \mathrm{~m}$. Local block fall occurs in the rock strata in boreholes. Therefore, it is inferred that the location is the upper limit of the caving zone above the goaf, and the height of the caving zone is about $18 \mathrm{~m}$. Figure $17(\mathrm{l})$ is the image of the probe lowered to a depth of $162.84 \mathrm{~m}$. The rock blocks piled up in disorder, gradually unable to see the surrounding situation in the borehole.

According to the existing mining geological data, the floor elevation of the goaf is $+284 \mathrm{~m}$ at the drilling position, and the maximum mining height of the coal seam is $6 \mathrm{~m}$. Therefore, the coal seam roof elevation is about $+290 \mathrm{~m}$.

Figure 18 shows the television observation results of boreholes in exploration area B. Figure $18(\mathrm{a})$ is a borehole 


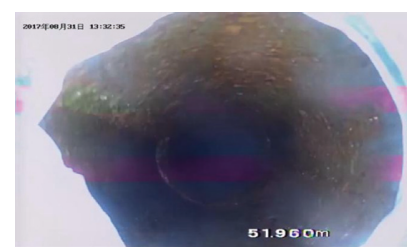

(a)

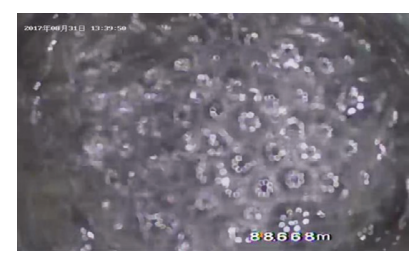

(e)

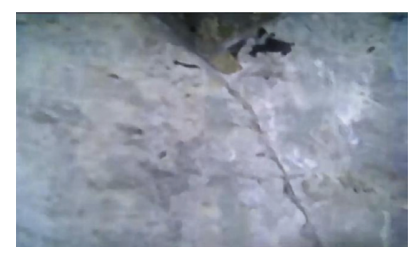

(i)

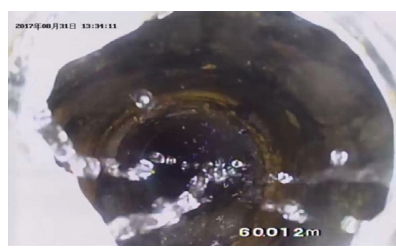

(b)

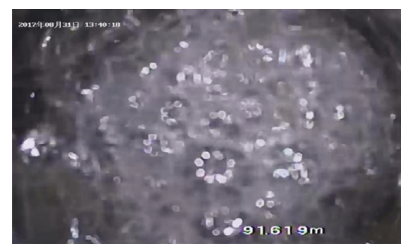

(f)

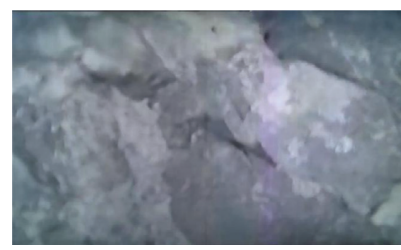

(j)

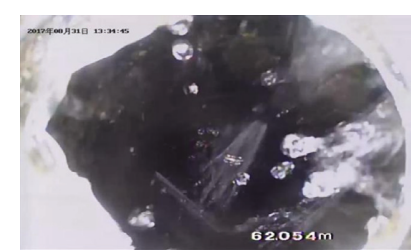

(c)

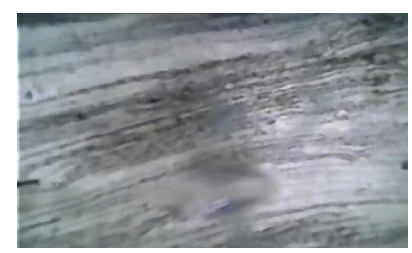

(g)

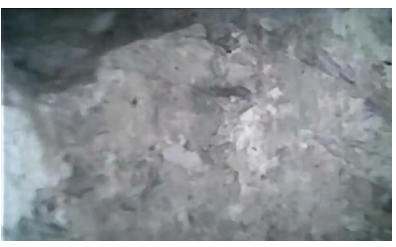

(k)

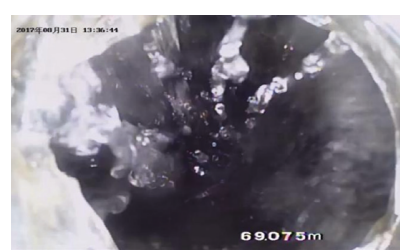

(d)

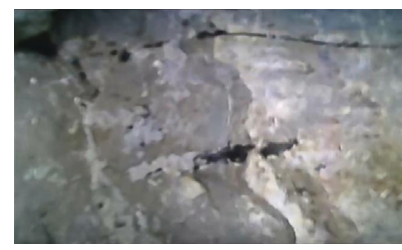

(h)

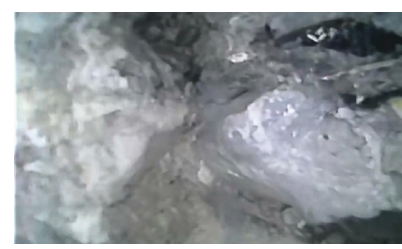

(1)

Figure 18: Television observation results of boreholes in exploration area B.

television image with the probe lowered to a depth of $51.96 \mathrm{~m}$. It can be seen that there is no water in the borehole. Figure 18(b) shows the image of the probe lowered to a depth of $60.01 \mathrm{~m}$. It can be seen that there is water leaking in the hole.

Figure $18(\mathrm{c})$ is the image of the probe lowered to a depth of $62.05 \mathrm{~m}$. It can be seen that the water in the hole increases obviously. Figure 18(d) is the image of the probe lowered to a depth of $69.07 \mathrm{~m}$. It can be seen that there is obvious water jet phenomenon in the hole and the water pressure is large. Figure 18(e) is the image of the probe lowered to a depth of $88.67 \mathrm{~m}$. The water surface in the hole can be clearly seen. Figure $18(\mathrm{f})$ is the image of the probe lowered to a depth of $91.61 \mathrm{~m}$. The reflection image of the probe light source on the water surface can be clearly seen. Therefore, the probe depth at this time can be determined as the water level of the goaf, and the water level elevation is $+371.49 \mathrm{~m}$. Figure $18(\mathrm{~g})$ is the image of the probe lowered to a depth of $105.32 \mathrm{~m}$. When the probe enters the water, the lateral camera of the probe starts to work, and the bedding surface of the rock mass in the hole wall can be seen. Figure 18(i) is an image of the probe lowered to a depth of $160.21 \mathrm{~m}$, with the elevation of $+302.89 \mathrm{~m}$. It is evident that the strata separating fracture can be seen. The site drilling does not return slurry at this elevation. It is inferred that the location is the upper bound of the waterconducting fracture zone above the goaf, and the height of the water-conducting fracture zone is about $65 \mathrm{~m}$. Figure 18(j) is the image of the probe lowered to a depth of $165.32 \mathrm{~m}$. There are irregular vertical secondary fissures in the strata of boreholes. Figure $18(\mathrm{k})$ is an image of the probe lowered to a depth of $198.86 \mathrm{~m}$, with the elevation of $+264.24 \mathrm{~m}$. Local block fall occurs in the rock strata in boreholes. Therefore, it is inferred that the location is the upper limit of the caving zone above the goaf, and the height of the caving zone is about $26 \mathrm{~m}$. Figure 18(1) is the image of the probe lowered to a depth of $207.78 \mathrm{~m}$. The rock blocks piled up in disorder, gradually unable to see the surrounding situation in the borehole.

According to the existing mining geological data, the floor elevation of the goaf is $+230 \mathrm{~m}$ at the drilling position, and the maximum mining height of the coal seam is $8 \mathrm{~m}$. Therefore, the coal seam roof elevation is about $+238 \mathrm{~m}$.

\section{Results and Discussion}

The distribution of mined-out areas and water accumulation in the coal mine are investigated in detail by using the comprehensive geophysical prospecting method of the transient electromagnetic method (TEM) and controlled source audio-frequency magnetotellurics (CSAMT). Finally, the distribution of coal mined-out areas in the exploration area is obtained, and the zoning map of comprehensive geophysical prospecting achievements in exploration areas $A$ and $B$ are shown in Figure 3. Based on the results of borehole exploration and the comprehensive analysis of the borehole image, it is concluded that the instantaneous water level elevation in goaf of exploration area $\mathrm{A}$ is about $+371 \mathrm{~m}$, the development height of the water-conducting fracture zone above goaf is about $44 \mathrm{~m}$, and the height of the caving zone is about $18 \mathrm{~m}$. In addition, the instantaneous water level elevation in goaf of exploration area B is about $+371 \mathrm{~m}$, the development height of the water-conducting fracture zone above goaf is about $65 \mathrm{~m}$, and the height of the caving zone is about $26 \mathrm{~m}$. The results of various geophysical methods are mutually corroborated, and the results are in good agreement. 
In addition, combined with the conclusions of similar detection methods in the past [30-32], it is found that the resolution and sensitivity of TEM and CSAMT are both high, and they can meet the necessary technical parameters for exploration and detection of underground goaf. Its exploration effect depends on the device type, receiving frequency, stacking times, and other related technical parameters. The underground goaf does show low-resistance anomaly according to the length of development time of the underground cavity and the degree of water accumulation [30]. It shows remarkable characteristics on the apparent resistivity section. Under the guarantee of suitable construction parameters and combined with existing geological data, the development characteristics of underground voids can be more accurately detected, and the survey effect is obvious $[30,31]$. It provides a good example for the application of the comprehensive geophysical prospecting method of TEM and CSAMT in the exploration of the underground cavity development area. And it has strong reference significance for the investigation and prevention of collapse geological environment disasters caused by such underground cavity.

\section{Conclusions}

The distribution of mined-out areas and water accumulation in the coal mine are investigated in detail by using the comprehensive geophysical prospecting method. Firstly, the unmanned aerial vehicle (UAV) aerial survey is used to accurately acquire the three-dimensional model of the slope in the key area of Yuanbaoshan open-pit coal mine, which provides basic information for the real-time visualization of the open-pit mine and the establishment of the engineering geological research profile. Secondly, the distribution of goaf in exploration areas $\mathrm{A}$ and $\mathrm{B}$ is detected by using the transient electromagnetic method (TEM) and controlled source audio-frequency magnetotellurics (CSAMT) combined geophysical methods. The results show that the electrical characteristics and low-resistance anomaly reflected by the two geophysical methods are in good agreement with each other. Finally, the borehole detection method is used to verify the goaf range obtained from comprehensive geophysical prospecting, and the results show good consistency. In addition, based on the results of borehole exploration and the comprehensive analysis of the borehole image, it is concluded that the instantaneous water level elevation in goaf of exploration area $\mathrm{A}$ is about $+371 \mathrm{~m}$, the development height of the water conducting fracture zone above goaf is about $44 \mathrm{~m}$, and the height of the caving zone is about $18 \mathrm{~m}$. In addition, the instantaneous water level elevation in goaf of exploration area $B$ is about $+371 \mathrm{~m}$, the development height of the water-conducting fracture zone above goaf is about $65 \mathrm{~m}$, and the height of the caving zone is about $26 \mathrm{~m}$. Overall, the results of comprehensive exploration show that through the use of the TEM and CSAMT method, combined with drilling detection methods, the purpose of accurate exploration of mined-out areas in coal mines can be achieved. Therefore, this comprehensive geophysical exploration research method provides a feasible and effective technical path for open-pit mines facing similar problems. It can be used for reference and extended to other mines or underground engineering exploration research.

\section{Data Availability}

The data used to support the findings of this study are available from the corresponding author upon request.

\section{Conflicts of Interest}

The authors declare that they have no conflicts of interest.

\section{Acknowledgments}

This work was financially supported by the research fund of the Henan Key Laboratory for Green and Efficient Mining \& Comprehensive Utilization of Mineral Resources (Henan Polytechnic University) (no. KCF201804) and the Doctoral Foundation of Henan Polytechnic University (no. B201922). All support is greatly appreciated.

\section{References}

[1] Z. H. Yang, G. Cui, Y. P. Fu, Y. Fang, and B. Yang, "Stability analysis of highway tunnel through mined-out area during excavation process," Advanced Materials Research, vol. 838841, pp. 1352-1358, 2013.

[2] X. Liang, Q.-G. Cheng, J.-J. Wu, and J.-M. Chen, "Model test of the group piles foundation of a high-speed railway bridge in mined-out area," Frontiers of Structural \& Civil Engineering, vol. 10, no. 4, pp. 488-498, 2016.

[3] Q. Yan and P. Y. Jia, "The application of grouting technology for governance of mined-out area under large channel," Advanced Materials Research, vol. 588-589, pp. 1922-1925, 2012.

[4] H. X. Wei, C. Wen-Feng, and C. L. Feng, "Analysis of characteristics of seismic section in goaf area," Progress in Geophysics, vol. 29, no. 4, pp. 1808-1814, 2014.

[5] Y. Shu, G. Xue, and W. Qiu, "Distinguishing multi-layer mined-out area through TEM," in Technology and Application of Environmental and Engineering Geophysics, pp. 127-133, Springer, Berlin, Germany, 2017.

[6] X. Liu, W. Zhou, and Z. Bai, "Vegetation coverage change and stability in large open-pit coal mine dumps in China during 1990-2015," Ecological Engineering, vol. 95, pp. 447-451, 2016.

[7] M. V. Kurlenya and A. S. Tanaino, "Energy analysis of openpit coal mining," Journal of Mining Science, vol. 33, no. 5, pp. 453-462, 1997.

[8] O. V. Mikhailov, J. Queen, and M. N. Toksöz, "Using borehole electroseismic measurements to detect and characterize fractured (permeable) zones," Geophysics, vol. 65, no. 4, pp. 1098-1112, 2000.

[9] M. J. Drury, A. M. Jessop, and T. J. Lewis, "The detection of groundwater flow by precise temperature measurements in boreholes," Geothermics, vol. 13, no. 3, pp. 163-174, 1984.

[10] D. A. Coles and F. D. Morgan, "A method of fast, sequential experimental design for linearized geophysical inverse problems," Geophysical Journal International, vol. 178, no. 1, pp. 145-158, 2010.

[11] A. Roy, "The method of continuation in mining geophysical interpretation," Geoexploration, vol. 4, no. 2, pp. 65-83, 1966. 
[12] C. Plati, A. Loizos, and V. Papavasiliou, "Inspection of railroad ballast using geophysical method," International Journal of Pavement Engineering, vol. 11, no. 4, pp. 309-317, 2010.

[13] C. Peng, L. F. Xue, Z. H. Liu, and H.-Y. Liu, "Application of the non-seismic geophysical method in the deep geological structure study of Benxi-Huanren area," Arabian Journal of Geosciences, vol. 9, no. 4, p. 310, 2016.

[14] P. Anbazhagan and T. G. Sitharam, Site Characterization of Bangalore Using Geophysical Method, Civil Engineering, Indian Institute of Science, Bengaluru, Karnataka, 2008.

[15] D. J. Daniels, "Ground penetrating radar," in Encyclopedia of $R F$ and Microwave Engineering, Wiley, Hoboken, NJ, USA, 2005.

[16] J. L. Davis and A. P. Annan, "Ground-penetrating radar for high-resolution mapping of soil and rock stratigraphy," Geophysical Prospecting, vol. 37, no. 5, pp. 531-551, 1989.

[17] Y. Yang, Y. Zheng, J. Chen et al., "Rayleigh wave phase velocity maps of Tibet and the surrounding regions from ambient seismic noise tomography," Geochemistry, Geophysics, Geosystems, vol. 11, no. 8, pp. 1020-1029, 2010.

[18] M. H. Loke, J. E. Chambers, D. F. Rucker, O. Kuras, and P. B. Wilkinson, "Recent developments in the direct-current geoelectrical imaging method," Journal of Applied Geophysics, vol. 95, no. 8, pp. 135-156, 2013.

[19] C. T. Brighton, "The semi-invasive method of treating nonunion with direct current," Orthopedic Clinics of North America, vol. 15, no. 1, pp. 33-45, 1984.

[20] J. E. Danielsen, E. Auken, F. Jørgensen, V. Søndergaard, and K. I. Sørensen, "The application of the transient electromagnetic method in hydrogeophysical surveys," Journal of Applied Geophysics, vol. 53, no. 4, pp. 181-198, 2003.

[21] F. Jørgensen, P. B. E. Sandersen, and E. Auken, "Imaging buried Quaternary valleys using the transient electromagnetic method," Journal of Applied Geophysics, vol. 53, no. 4, pp. 199-213, 2003.

[22] Z.-H. Jiang, J.-H. Yue, and S.-C. Liu, "Prediction technology of buried water-bearing structures in coal mines using transient electromagnetic method," Journal of China University of Mining and Technology, vol. 17, no. 2, pp. 164-167, 2007.

[23] J.-C. Yu, Y.-Z. Wang, J. Liu, and X.-B. Zeng, "Time-depth conversion of transient electromagnetic method used in coal mines," Journal of China University of Mining and Technology, vol. 18, no. 4, pp. 546-550, 2008.

[24] E. Gajda-Zagórska, R. Schaefer, M. Smołka, M. Paszyński, and D. Pardo, "A hybrid method for inversion of 3D DC resistivity logging measurements," Natural Computing, vol. 14, no. 3, pp. 355-374, 2015.

[25] G. Xing, H. Wang, and Z. Ding, "A new combined measurement method of the electromagnetic propagation resistivity logging," IEEE Geoscience and Remote Sensing Letters, vol. 5, no. 3, pp. 430-432, 2008.

[26] A. T. Basokur, T. M. Rasmussen, C. Kaya, Y. Altun, and K. Aktas, "Comparison of induced polarization and controlled-source audio-magnetotellurics methods for massive chalcopyrite exploration in a volcanic area," Geophysics, vol. 62, no. 4, pp. 1087-1096, 1997.

[27] L. Cagniard, "Basic theory of the magneto-telluric method of geophysical prospecting," Geophysics, vol. 18, no. 3, pp. $605-635,1953$.

[28] A. T. Başokur, "Definitions of apparent resistivity for the presentation of magnetotelluric sounding data," Geophysical Prospecting, vol. 42, no. 2, pp. 141-149, 1994.
[29] Y. Kanaori, "The observation of crack development around an underground rock chamber by borehole television system," Rock Mechanics and Rock Engineering, vol. 16, no. 2, pp. 133-142, 1983.

[30] P. L. Gong and W. Li, "Application on transient electromagnetic method in collapse hazard of goaf: take the investigation of the goaf in Shendong coal mine as an example," Journal of Geomechanics, vol. 24, no. 3, pp. 416-423, 2018.

[31] D. Y. Wang, T. L. Li, Y. Gao et al., "The application of CSAMT and TEM to exploration buried deposits in Longhu mountain area at Tongling, Anhui Province," Journal of Jilin University (Earth Science Edition), vol. 39, no. 6, pp. 1134-1140, 2009.

[32] A. Younis, G. El-Qady, M. Abd Alla et al., "AMT and CSAMT methods for hydrocarbon exploration at Nile Delta, Egypt," Arabian Journal of Geosciences, vol. 8, no. 4, pp. 1965-1975, 2015. 


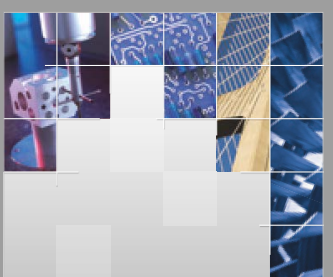

\section{Enfincering}
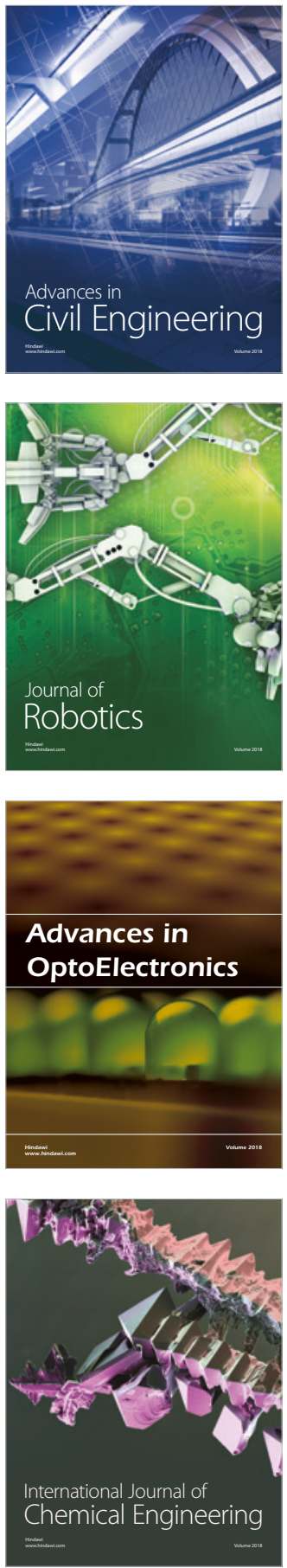

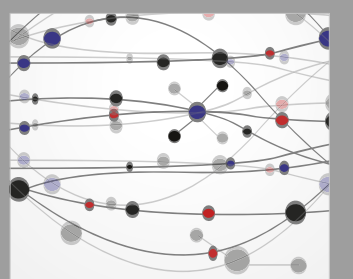

\section{Rotating \\ Machinery}

The Scientific World Journal

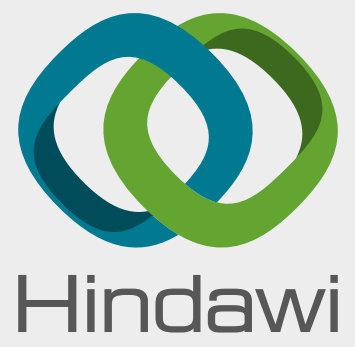

Submit your manuscripts at

www.hindawi.com
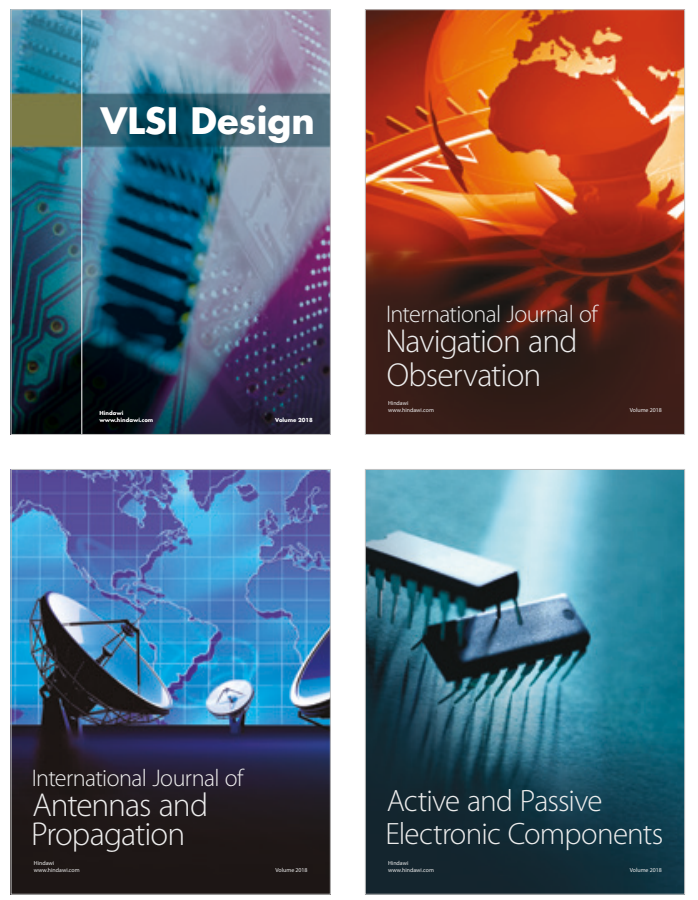
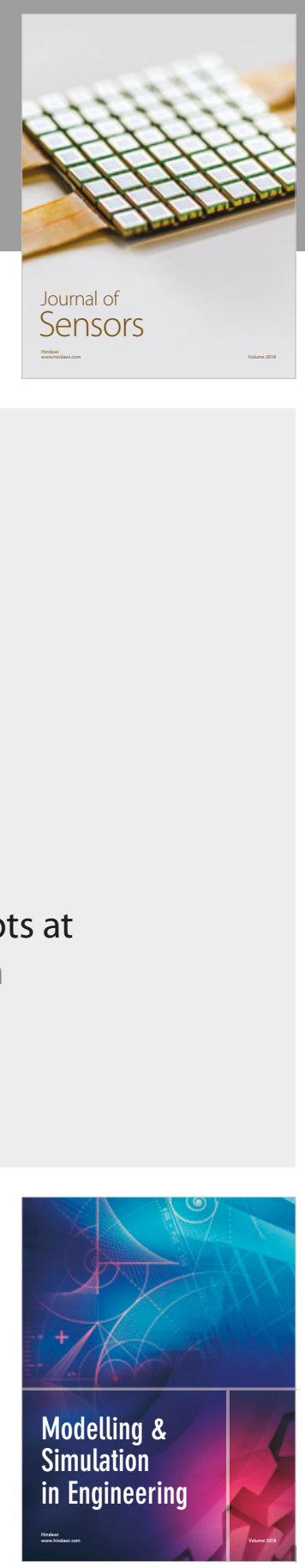

\section{Advances \\ Multimedia}
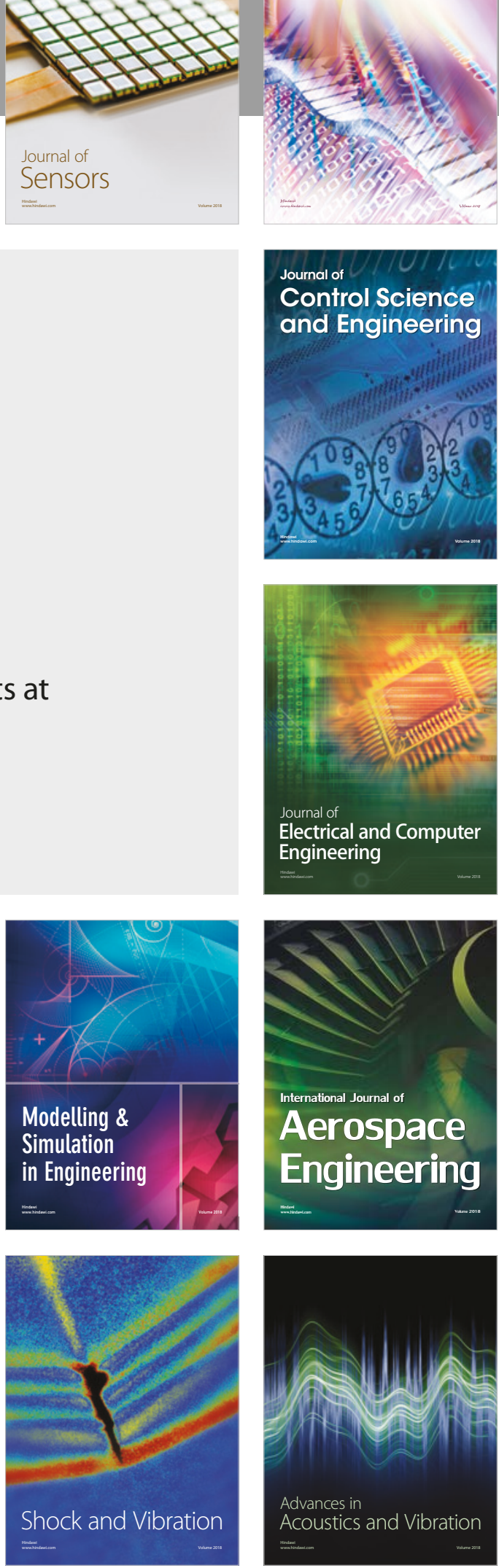